BG Thomas and M. Bellet, ASM Handbook, Chap 15, S. Viswanathan ed., submitted October, 2006

\title{
Modeling of Stress, Distortion and Hot Tearing
}

\author{
Brian G. Thomas ${ }^{1}$, Michel Bellet ${ }^{2}$ \\ ${ }^{1}$ Department of Mechanical Science \& Engineering, University of Illinois (UIUC), \\ 1206 West Green St., Urbana, Illinois, USA, 60801. bgthomas@uiuc.edu \\ ${ }^{2}$ Ecole des Mines de Paris, Centre de Mise en Forme des Matériaux (CEMEF), \\ BP 207, 06904 Sophia Antipolis, France. michel.bellet@ensmp.fr
}

\section{Introduction}

The application of numerical methods to the mechanical modeling in solidification analysis has received a continuously growing interest over the last twenty years. After having concentrated their efforts on the thermal and microstructural predictions, research teams have been more and more interested in the coupled thermomechanical analysis. These developments have been motivated by the efforts done by the casting industry to increase the quality of final products while lowering the costs. Manufacturers are then interested in the development of new numerical tools able to model the thermomechanical response of castings during the processes. Accurate calculation of stress and distortions during casting is just the first step, however, as engineers are more interested in their practical consequences. These include residual stress and distortion, and defects such as segregation and the formation of cracks such as hot tears. As computing power and software tools advance, it is becoming increasingly possible to perform useful mechanical analysis of castings and these important related behaviors.

Despite the considerable progress in computational structural mechanics, and in the capabilities of intensive computing, the thermomechanical analysis of castings is still a challenge nowadays, for the following reasons:

- Many interacting physical phenomena are involved in stress-strain formation. Stress arises primarily from the mismatch of strains caused by the steep temperature gradients of solidification, and depends on the time- and microstructure- dependent inelastic flow of the material.

- Predicting distortions and residual stresses in cast products means being able to describe and calculate the history of the cast product and its environment on huge temperature intervals. This makes the mechanical problem highly non-linear, involving liquid-solid interaction and quite complex constitutive equations. Also the identification of reliable values of the numerous parameters involved in those relations is a very difficult task.

- The coupling between the thermal and the mechanical problems is an additional difficulty. This coupling comes from the mechanical interaction between the casting and the mold components, through gap formation or the build-up of contact pressure, modifying locally the heat exchange. This adds some complexity to the non-linear heat transfer resolution.

- As it does not make sense to perform such analyses without accounting for the presence of molds and their interaction with the castings, the problem to be solved is multidomain, often involving numerous deformable and interacting components. 
BG Thomas and M. Bellet, ASM Handbook, Chap 15, S. Viswanathan ed., submitted October, 2006

- Shapes of cast parts are by essence complex, which first brings out frequent difficulties regarding the interface between CAD design and the mechanical solvers, and second demands great computational resources.

- In the case of solidification of semi-finished products, by continuous casting, the computational demand is also outstanding, because of the characteristic dimensions to be considered: meters, tens of meters.

This chapter summarizes some of the issues and approaches in performing computational analyses of mechanical behavior, distortion and hot-tearing during solidification. The governing equations are presented first, followed by a brief description of the methods used to solve them. Finally, a few examples of recent applications in shape castings and continuous casting are introduced.

\section{Constitutive models for metallic alloys in liquid, mushy and solid state}

The modeling of mechanical behavior requires solution of the equilibrium equations (relating force and stress), constitutive equations (relating stress and strain) and compatibility equations (relating strain and displacement). In casting analysis, the cast material may be in the liquid, mushy or solid state. Therefore, mechanical modeling of casting processes has to consider constitutive models for each of these states.

\subsection{Liquid state: Newtonian model}

Metallic alloys are generally considered as Newtonian fluids. Including thermal dilatation effects, the constitutive equation can be expressed as follows.

$$
\dot{\boldsymbol{\varepsilon}}=\frac{1}{2 \mu_{l}} \boldsymbol{s}-\frac{1}{3 \rho} \frac{\mathrm{d} \rho}{\mathrm{d} t} \boldsymbol{I}
$$

in which the strain rate tensor $\dot{\boldsymbol{\varepsilon}}$ is split into a mechanical part, showing the linear relation between the strain rate tensor and the stress deviator $s$, and a thermal part. In this equation, $\mu_{l}$ is the dynamic viscosity of the liquid alloy, $\rho$ is the density, and $\boldsymbol{I}$ is the identity tensor. Taking the trace of this expression, $\operatorname{tr} \dot{\boldsymbol{\varepsilon}}=\nabla \cdot \boldsymbol{v}$, the mass conservation equation is recovered:

$$
\frac{\mathrm{d} \rho}{\mathrm{d} t}+\rho \nabla \cdot \boldsymbol{v}=\frac{\partial \rho}{\partial t}+\nabla \cdot(\rho \boldsymbol{v})=0
$$

In casting processes, the liquid flow may be turbulent, even after mold filling. This may occur because of buoyancy forces or forced convection like in jets coming out of the nozzle outlets in continuous casting processes. The most accurate approach, direct numerical simulation, is generally not feasible for industrial processes, owing to their complex shaped domains and high turbulence. To compute just the large-scale flow features, turbulence models are used, that increase the liquid viscosity according to different models of the small-scale phenomena. These models include the simple "mixing length" models, the two-equation models such as $k-\varepsilon$, and large eddy simulation (LES) models, which have been compared with each other and with measurements of continuous casting. ${ }^{1-3}$

\subsection{Mushy state: Non-Newtonian model}

Metallic alloys in the mushy state are very complex two-phase liquid-solid media. Their mechanical response is highly dependent on the local microstructural evolution, which involves several complex physical phenomena. To overcome this difficulty, the mushy state may be considered in a first approach as a single continuum. The mushy material is then modeled as a non-Newtonian fluid, according to the following equations: 
BG Thomas and M. Bellet, ASM Handbook, Chap 15, S. Viswanathan ed., submitted October, 2006

$$
\left\{\begin{array}{l}
\dot{\boldsymbol{\varepsilon}}=\dot{\boldsymbol{\varepsilon}}^{v p}+\dot{\boldsymbol{\varepsilon}}^{\text {th }} \\
\dot{\boldsymbol{\varepsilon}}^{v p}=\frac{3}{2 K}\left(\dot{\boldsymbol{\varepsilon}}_{e q}\right)^{1-m} \boldsymbol{S} \\
\dot{\boldsymbol{\varepsilon}}^{\text {th }}=-\frac{1}{3 \rho} \frac{\mathrm{d} \rho}{\mathrm{d} t} \boldsymbol{I}
\end{array}\right.
$$

in which $K$ is the viscoplastic consistency and $m$ the strain rate sensitivity. Denoting $\sigma_{e q}=\sqrt{3 / 2} s_{i j} s_{i j}$ the von Mises equivalent stress scalar, and $\dot{\varepsilon}_{e q}=\sqrt{2 / 3} \dot{\varepsilon}_{i j}^{v p} \dot{\varepsilon}_{i j}^{v p}$ the von Mises equivalent strain rate scalar, Eq. (3) yields the well known power law: $\sigma_{e q}=K\left(\dot{\varepsilon}_{e q}\right)^{m}$. It can be noticed that the preceding Newtonian model is actually a particular case of the non-Newtonian one: Eq. (1) can be derived from Eq. (3) taking $m=1$ and $K=3 \mu_{l}$. The solidification shrinkage is included in the third equation, as we can write in the solidification interval $\rho=g_{s} \rho_{S}+g_{l} \rho_{L}$ with $\rho_{S}$ and $\rho_{L}$ the densities at the solidus and liquidus temperatures, respectively. Hence, we have:

$$
\operatorname{tr} \dot{\boldsymbol{\varepsilon}}^{\text {th }}=-\frac{1}{\rho} \frac{\mathrm{d} \rho}{\mathrm{d} t}=-\frac{1}{\rho}\left(\rho_{S}-\rho_{L}\right) \frac{\mathrm{d} g_{s}}{\mathrm{~d} t} \approx \frac{\rho_{L}-\rho_{S}}{\rho_{L}} \frac{\mathrm{d} g_{s}}{\mathrm{~d} t}
$$

\subsection{Solid state: elastic-visco-plastic models}

In the solid state, metallic alloys can be modeled either as elastic-plastic or elastic-viscoplastic materials. In this latest class of models, one of the simpler is expressed as follows, but it should be mentioned that a lot of models of different complexity can be found in the literature. ${ }^{4,5}$

$$
\left\{\begin{array}{l}
\dot{\boldsymbol{\varepsilon}}=\dot{\boldsymbol{\varepsilon}}^{e l}+\dot{\boldsymbol{\varepsilon}}^{i n}+\dot{\boldsymbol{\varepsilon}}^{t h} \\
\dot{\boldsymbol{\varepsilon}}^{e l}=\frac{1+v}{E} \dot{\boldsymbol{\sigma}}-\frac{v}{E} \operatorname{tr}(\dot{\boldsymbol{\sigma}}) \boldsymbol{I}+\dot{T} \frac{\partial}{\partial T}\left(\frac{1+v}{E}\right) \boldsymbol{\sigma}-\dot{T} \frac{\partial}{\partial T}\left(\frac{v}{E}\right) \operatorname{tr}(\boldsymbol{\sigma}) \boldsymbol{I} \\
\dot{\boldsymbol{\varepsilon}}^{i n}=\frac{3}{2 \sigma_{e q}}\left\langle\frac{\sigma_{e q}-\sigma_{0}}{K}\right)^{1 / m} \boldsymbol{s} \\
\dot{\boldsymbol{\varepsilon}}^{\text {th }}=-\frac{1}{3 \rho} \frac{\mathrm{d} \rho}{\mathrm{d} t} \boldsymbol{I}
\end{array}\right.
$$

The strain rate tensor $\dot{\boldsymbol{\varepsilon}}$ is split into an elastic component, an inelastic (non reversible) component, and a thermal component. Equation (5b) yields the hypoelastic Hooke's law, where $E$ is Young's modulus, $v$ the Poisson's coefficient, and $\dot{\sigma}$ a time derivative of the stress tensor $\boldsymbol{\sigma}$. Equation (5c) gives the relation between the inelastic strain rate tensor $\dot{\boldsymbol{\varepsilon}}^{\text {in }}$ and the stress deviator, $\boldsymbol{s}$, in which $\sigma_{0}$ denotes the scalar static yield stress, below which no inelastic deformation occurs (the expression between brackets is reduced to zero when negative). In these equations, the temperature dependency of all the involved variables should be considered. The effect of strain hardening may appear in such a model by the increase of the static yield stress $\sigma_{0}$ and the plastic consistency $K$ with the accumulated inelastic strain $\varepsilon_{e q}$, or with another state variable that is representative of the material structure. The corresponding scalar equation relating stress and inelastic strain rate von Mises invariants is:

$$
\sigma_{e q}=\sigma_{0}+K\left(\dot{\varepsilon}_{e q}\right)^{m}
$$

Inserting this into Eq. (5c) simplifies it to: 
BG Thomas and M. Bellet, ASM Handbook, Chap 15, S. Viswanathan ed., submitted October, 2006

$$
\dot{\boldsymbol{\varepsilon}}^{i n}=\frac{3 \dot{\varepsilon}_{e q}}{2 \sigma_{e q}} \boldsymbol{s}, \text { or, in incremental form, } \mathrm{d} \boldsymbol{\varepsilon}^{i n}=\frac{3 \mathrm{~d} \varepsilon_{e q}}{2 \sigma_{e q}} \boldsymbol{s}
$$

Although metallic alloys show a significant strain rate sensitivity at high temperature, they are often modelled in the literature using elastic-plastic models, neglecting this important effect. In this case, Eq. (7) still holds, but the flow stress is then independent of the strain rate. It may depend on the accumulated plastic strain because of strain hardening.

\section{$2.4 \quad$ Implementation Issues}

As stresses and distortions are generated mainly in the solid phase, the mechanical modeling of a cast part may be restricted to its solidified region at any instant. However, this approach, often used in the literature, has several drawbacks. First, doing so, the volumetric shrinkage that affects the mushy zone cannot be taken into account. Second, the liquid and mushy regions may alter the distortion and stress of the solidified regions. Finally, the mechanical behavior of the mushy zone is of crucial importance to quality problems. Thus, it is preferable to consider the entire casting, including the mushy and liquid regions.

To avoid managing different constitutive equations for the different states, numerous authors have modeled the liquid and mushy state behavior simply by lowering the value of the Young modulus and taking Poisson coefficient close to $1 / 2$, using then a single elastic-viscoplastic (or elastic-plastic) constitutive model for the entire casting ${ }^{6-13}$ However, this approach may suffer from numerical difficulty, and furthermore fails to account accurately for the significant thermal dilatation and shrinkage that affect the mushy and liquid regions.

To overcome these difficulties, other authors use a different constitutive equation for the different physical states of the alloy. The whole casting is modeled, and the constitutive equation is chosen according to the local state. One implementation ${ }^{14}$ simply changes the constants in Eq. (5) to model the different states. Using a physically-reasonable (high) value for the elastic modulus, and setting $m=1, \sigma_{0}=0$, and $K=\mu_{l}$ allows Eq. (5) to approximate Eq. (3) for a Newtonian fluid, as the generated elastic strains are very small. Another approach ${ }^{15,16}$ uses a viscoplastic equation for the mushy and liquid states and an elastic-viscoplastic equation for the solid state.

In each of these previous mechanical models, the liquid, mushy, and solid zones are considered as a single continuum. The velocity of the liquid phase is not distinguished from the velocity of the solid phase, and the individual dendrites and grain boundaries are not resolved, so fluid feeding, porosity formation, and hot tearing are clearly oversimplified. In the context of stress-strain prediction, this approximation seems valid. To predict defect formation from first principles, however, might require a multiphase approach, involving the different phases, including liquid, solid, and even gas. Recent approaches, like those developed by Nicolli et $\mathrm{al}^{17}$ and Fachinotti et $\mathrm{al}^{18}$ take into account the mechanical interaction between a deformable solid skeleton and the liquid phase, the momentum transfer between the two phases being expressed by a Darcy law.

\subsection{Example of Constitutive Equations}

Material property data are needed for the specific alloy being modeled and in a form suitable for the constitutive equations just discussed. This presents a significant challenge for quantitative mechanical analysis, because measurements are not presented in this form, and only rarely supply enough information on the conditions to allow transformation to an alternate form. As an example, the following elastic-viscoplastic constitutive equation was developed for the austenite phase of steel by Kozlowski et al ${ }^{19}$ by fitting constant strain-rate tensile tests from Wray ${ }^{20,21}$ and constant-load creep tests from Suzuki et al ${ }^{22}$ to the form required in Eqs. (5)-(7). 
BG Thomas and M. Bellet, ASM Handbook, Chap 15, S. Viswanathan ed., submitted October, 2006

$$
\dot{\varepsilon}_{e q}=f_{\% C}\left\langle\sigma_{e q}-\sigma_{0}\right\rangle^{1 / m} \exp \left(-\frac{4.465 \times 10^{4}}{T}\right)
$$

where

$$
\begin{aligned}
& f_{\% C}=4.655 \times 10^{4}+7.14 \times 10(\% C)+1.2 \times 10^{4}(\% C)^{2} \\
& \sigma_{0}=\left(130.5-5.128 \times 10^{-3} T\right) \varepsilon_{e q}^{f_{2}} \\
& f_{2}=-0.6289+1.114 \times 10^{-3} T \\
& 1 / m=8.132-1.54 \times 10^{-3} T \\
& \text { with } T[\mathrm{~K}], \sigma_{e q}, \sigma_{0}[\mathrm{MPa}]
\end{aligned}
$$

This equation, and a similar one for delta-ferrite, have been implemented into the finite-element codes CON2D ${ }^{14}$ and THERCAST ${ }^{23}$ and applied to investigate several problems involving mechanical behavior during continuous casting.

Elastic modulus is a crucial property that decreases with increasing temperature. It is difficult to measure at the high temperatures important to casting, owing to the susceptibility of the material to creep and thermal strain during a standard tensile test, which results in excessively low values. Higher values are obtained from high-strain-rate tests, such as ultrasonic measurements. ${ }^{24}$ Elastic modulus measurements in steels near the solidus temperature range from $\sim 1 \mathrm{GPa}^{25}$ (Puhringer, 1976) to $44 \mathrm{GPa}^{26}$ Typical modulus data by Mizukami et $\mathrm{al}^{27}$ include values $\sim 10 \mathrm{GPa}$ near the solidus and have been used in previous analyses. ${ }^{28,}$

The density needed to compute thermal strain in Eqs. (1), (4) or (5d) can be found from a weighted average of the values of the different solid and liquid phases, based on the local phase fractions. For the example of plain low carbon steel, the following equations were compiled ${ }^{14}$ based on the solid data for ferrite $(\alpha)$, austenite $(\gamma)$, and delta $(\delta)$ from Harste et $\mathrm{al}^{30,31}$ and the liquid $(l)$ measurements from Jimbo and $\mathrm{Cramb}^{32}$ :

$$
\begin{aligned}
& \rho\left(\mathrm{kg} / \mathrm{m}^{3}\right)=\rho_{\alpha} f_{\alpha}+\rho_{\gamma} f_{\gamma}+\rho_{\delta} f_{\delta}+\rho_{l} f_{l} \\
& \rho_{\alpha}=7881-0.324 T\left({ }^{o} \mathrm{C}\right)-3 \times 10^{-5} T\left({ }^{o} C\right)^{2} \\
& \rho_{\gamma}=\frac{100\left[8106-0.51 T\left({ }^{o} \mathrm{C}\right)\right]}{[100-(\% C)][1+0.008(\% \mathrm{\%})]^{3}} \\
& \rho_{\delta}=\frac{100\left[8011-0.47 T\left({ }^{o} \mathrm{C}\right)\right]}{[100-(\% C)][1+0.013(\% \mathrm{O})]^{3}} \\
& \rho_{l}=7100-73(\% \mathrm{C})-[0.8-0.09(\% C)]\left[T\left({ }^{o} \mathrm{C}\right)-1550\right]
\end{aligned}
$$

Specialized experiments to measure mechanical properties for use in computational models will be an important trend for future research in this field.

\section{Thermomechanical coupling}

Coupling between the thermal and mechanical analyses arises from several sources. First, regarding the mechanical problem, besides the strain rate due to thermal expansion and solidification shrinkage, the material parameters of the preceding constitutive equations strongly depend on temperature and phase fractions, as shown in the previous section. Second, in the heat transfer problem, the thermal exchange between the casting and the mold strongly depends on local conditions such as the contact pressure or the presence of a gap between them (as a result of thermal expansion and solidification shrinkage). This is explained in the next two paragraphs. 
BG Thomas and M. Bellet, ASM Handbook, Chap 15, S. Viswanathan ed., submitted October, 2006

\subsubsection{Air gap formation: conductive-radiative modeling}

In the presence of a gap between the casting and the mold, resulting from their relative deformation, the heat transfer results from concurrent conduction through the gas within the gap and from radiation. The exchanged thermal flux, $q_{g a p}$, can then be written:

$$
q_{g a p}=\frac{k_{g a s}}{g}\left(T_{c}-T_{m}\right)+\frac{\sigma\left(T_{c}^{4}-T_{m}{ }^{4}\right)}{\frac{1}{\varepsilon_{c}}+\frac{1}{\varepsilon_{m}}-1}
$$

with $k_{\text {gas }}(T)$ the thermal conductivity of the gas, $g$ the gap thickness, $T_{c}$ and $T_{m}$ the local surface temperature of the casting and mold, respectively, $\varepsilon_{c}$ and $\varepsilon_{m}$ their gray-body emissivities, $\sigma$ the StefanBoltzmann constant. It is to be noted that the conductive part of the flux can be written in more detail to take into account the presence of coating layers on the mold surface: conduction through a medium of thickness $g_{\text {coat }}$, of conductivity $k_{\text {coat }}(T)$. It can be seen that the first term tends to infinity as the gap thickness tends to zero: this expresses a perfect contact condition, $T_{c}$ and $T_{m}$ tending towards a unique interface temperature. The reality is somewhat different, showing always non perfect contact conditions. Therefore, the conductive heat exchange coefficient $h_{\text {cond }}=k_{\text {gas }} / g$ should be limited by a finite value $h_{0}$, corresponding to the "nogap" situation, and depends on the roughness of the casting surface. A recent benchmark exercise has demonstrated the significant impact of the consideration of gap formation on temperature prediction in shape casting. ${ }^{33}$ Specific examples of these gap heat transfer laws are provided elsewhere for continuous casting with oil lubrication, ${ }^{34}$ and continuous casting with mold flux. ${ }^{35}$

\subsubsection{Effective contact: heat transfer as a function of contact pressure}

In the case of an effective contact, the conductive heat flux increases with the contact pressure according to a power law. ${ }^{36}$ Still denoting $h_{0}$ the heat exchange coefficient corresponding to no gap and no contact pressure, we can write, in order to ensure the continuity with the gap situation:

$$
q_{\text {contact }}=\left(h_{0}+A p_{c}{ }^{B}\right)\left(T_{c}-T_{m}\right)
$$

with $p_{c}$ the contact pressure, $A$ and $B$ two parameters which depend on the materials, the presence of coating or lubricating agent, the surface roughness, and the temperature. The parameters and possibly the laws governing their evolution need to be determined experimentally.

Figure 1 is a graphic representation of the heat exchange coefficient in both cases. It should be noted that a smoothing method around the neutral position has been suggested by Laschet et al. ${ }^{37}$

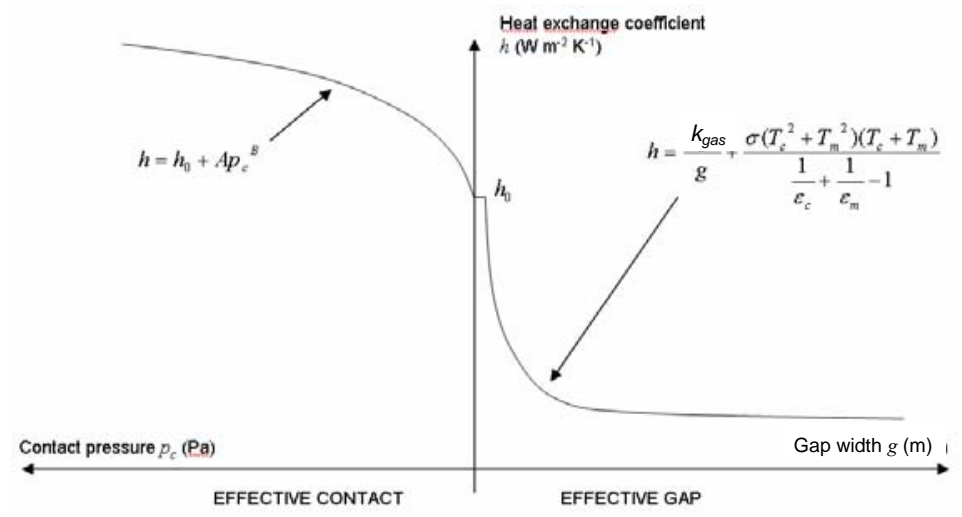

Figure 1. Modeling of the local heat transfer coefficient in the gap and effective contact situations.

\section{$4 \quad$ Numerical solution}


BG Thomas and M. Bellet, ASM Handbook, Chap 15, S. Viswanathan ed., submitted October, 2006

We focus here on the resolution of the momentum conservation, from which distortions and stresses can be calculated. The energy conservation is not discussed in this paper.

\subsection{Momentum conservation}

At any time, and in any location of the solidifying material, whatever its current state (liquid, mushy or solid) the momentum conservation is expressed by:

$$
\nabla \cdot \boldsymbol{\sigma}+\rho \boldsymbol{g}-\rho \boldsymbol{\gamma}=\nabla \cdot \boldsymbol{s}-\nabla p+\rho \boldsymbol{g}-\rho \boldsymbol{\gamma}=0
$$

where $\boldsymbol{g}$ denotes the gravity and $\gamma$ the acceleration. The acceleration is actually noticeable only in liquid pools, when they are affected by convection.

The weak form of the preceding equation can be obtained. Keeping the velocity and pressure as primitive unknown variables, it is written $\mathrm{as}^{38}$ :

$$
\left\{\begin{array}{l}
\forall \boldsymbol{v}^{*} \int_{\Omega} \boldsymbol{s}(\boldsymbol{v}): \dot{\boldsymbol{\varepsilon}}^{*} d V-\int_{\Omega} p \nabla \cdot \boldsymbol{v}^{*} d V-\int_{\partial \Omega} \boldsymbol{T} \cdot \boldsymbol{v}^{*} d S-\int_{\Omega} \rho \boldsymbol{g} \cdot \boldsymbol{v}^{*} d V+\int_{\Omega} \rho \frac{\mathrm{d} \boldsymbol{v}}{\mathrm{d} t} \cdot \boldsymbol{v}^{*} d V=0 \\
\forall p^{*} \int_{\Omega} p^{*} \operatorname{tr} \dot{\boldsymbol{\varepsilon}}^{i n} d V=0
\end{array}\right.
$$

where $\boldsymbol{T}$ is the external stress vector, $\boldsymbol{g}$ the gravity. In such a velocity-pressure formulation, the second equation is a weak form of the incompressibility of inelastic deformations.

\subsection{Finite element formulation and numerical implementation}

The thermal-mechanical modeling equations just presented must be solved numerically, owing to the complex shape of the casting process domain. Although finite-difference approaches are popular for fluid flow and solidification analysis to compute the temperature field, the finite element formulation is preferred for the mechanical analysis, owing to its historical advantages with unstructured meshes and accurate implicit solution of the resulting simultaneous algebraic equations.

Spatial discretization using finite elements, combined with time discretization using finite differences, yield a set of non-linear equations $\boldsymbol{R}_{\text {mech }}(\boldsymbol{V}, \boldsymbol{P})=0$, in which the unknowns are the velocity components and the pressure value at each node of the finite element mesh. In some formulations, the incompressibility condition is directly included in the momentum equation using a penalty technique to enforce it. This results in a velocity formulation $\boldsymbol{R}_{\text {mech }}(\boldsymbol{V})=0$ in which the velocity field is the only unknown, but which is known to give rise to pressure locking problems when the incompressible inelastic strains become too large. ${ }^{39}$ In the preceding formulations, nodal velocities can be replaced by nodal displacements, as they are linked by the time integration scheme.

Solving the previous global finite element non-linear system $\boldsymbol{R}_{\text {mech }}=0$ can be a daunting task that is subject to significant convergence difficulties. Generally, it is solved using a full or modified NewtonRaphson method, ${ }^{40}$ which iterates to minimize the residual error in Eq. (13). These methods require local consistent tangent operators $\partial \mathbf{s} / \partial \dot{\boldsymbol{\varepsilon}}$ and $\partial p / \partial \dot{\boldsymbol{\varepsilon}}$ in order to form a global consistent stiffness matrix $\partial \boldsymbol{R}_{\text {mech }} / \partial \boldsymbol{V} \cdot{ }^{39}$

At the local level, when the constitutive equations involve strain rate dependency, then an algorithm is also required to integrate the constitutive equations to provide an estimate of $s(\dot{\varepsilon})$ and $p(\dot{\varepsilon})$ and the previously mentioned tangent operators. When the constitutive equations are highly non-linear, it is very useful to employ an implicit algorithm to provide better estimates of inelastic strain at the local level. Many methods have been developed ${ }^{41-43}$ which require solving two or more ordinary differential equations at each local integration point. The bounded Newton-Raphson method developed by Lush $\mathrm{et}^{\mathrm{at}}{ }^{42}$ and later improved upon by $\mathrm{Zhu}^{43}$ was implemented into a user-subroutine in ABAQUS and found to improve greatly accelerate the solution. ${ }^{44}$ 
BG Thomas and M. Bellet, ASM Handbook, Chap 15, S. Viswanathan ed., submitted October, 2006

Alternatively, an operator splitting method can be used to march through time by alternating between the global and local levels without iteration at either level. ${ }^{14}$; Koric, 2005 \#3263\}

\subsection{Boundary conditions: modeling of contact conditions. Multidomain approaches}

At the interface between the solidifying material and the mold, a unilateral contact condition (i.e. including contact release) generally applies:

$$
\left\{\begin{array}{l}
\boldsymbol{\sigma} \boldsymbol{n} \cdot \boldsymbol{n} \leq 0 \\
g \geq 0 \\
(\boldsymbol{\sigma n} \cdot \boldsymbol{n}) g=0
\end{array}\right.
$$

where $g$ is the local interface gap width (positive when air gap exists effectively) and $\boldsymbol{n}$ is the local outward unit normal to the part. The fulfillment of Eq. (14) can be obtained by means of a penalty condition, which consists in applying a normal stress vector $\boldsymbol{T}$ proportional to the normal distance or the normal velocity difference (or a combination of both) via a penalty constant $\chi_{p}$ :

$$
\boldsymbol{T}=\boldsymbol{\sigma n}=-\chi_{p}\left\langle\left(\boldsymbol{v}-\boldsymbol{v}_{\text {mold }}\right) \cdot \boldsymbol{n}\right\rangle \boldsymbol{n}
$$

Different methods of local adaptation of the penalty coefficient $\chi_{p}$ have been developed, among which the augmented Lagrangian method. ${ }^{45}$ More complex and computationally expensive methods, such as the use of Lagrange multipliers may also be used. ${ }^{46}$

The possible tangential friction effects between part and mold can be taken into account by a friction law, such as a Coulomb model for instance. In this case, the previous stress vector has a tangential component, $\boldsymbol{T}_{\tau}$, given by:

$$
\boldsymbol{T}_{\tau}=-\mu_{f} p_{c} \frac{1}{\left\|\boldsymbol{v}-\boldsymbol{v}_{\text {mold }}\right\|}\left(\boldsymbol{v}-\boldsymbol{v}_{\text {mold }}\right)
$$

where $p_{c}=-\sigma_{n}=\sigma \boldsymbol{n} \cdot \boldsymbol{n}$ is the contact pressure, and $\mu_{f}$ the friction coefficient.

The previous approach can be extended to the multidomain context in order to account for the deformation of mold components. The local stress vectors calculated by Eq. (15) can be applied onto the surface of the mold, contributing then to its deformation. For most casting processes, the mechanical interaction between the cast product and the mold is sufficiently slow (i.e. its characteristic time remains significant with respect to the process time) to permit a staggered scheme within each time increment: the mechanical problem is successively solved in the cast product and in the different mold components. A global updating of the different configurations is then performed at the end of the time increment. This simple approach gives access to a prediction of the local air gap size $g$, or alternatively of the local contact pressure $p_{c}$, that are used in the expressions of the heat transfer coefficient, according to Eqs. (10) and (11). ${ }^{47}$

\subsection{Treatment of the regions in the solid, mushy and liquid states}

\subsubsection{Solidified regions: Lagrangian formulation}

In casting processes, the solidified regions generally encounter small deformations. It is thus natural to embed the finite element domain into the material, with each node of the computational grid corresponding with the same solid particle during its displacement. The boundary of the mesh corresponds then to the surface of the casting. This method, called Lagrangian formulation, provides the best accuracy when computing the gap forming between the solidified material and the mold. It is also the more reliable and convenient method for time integration of highly non-linear constitutive equations, such as elastic-(visco)plastic laws presented in section 2.3. 
BG Thomas and M. Bellet, ASM Handbook, Chap 15, S. Viswanathan ed., submitted October, 2006

\subsubsection{Mushy and liquid regions: ALE modeling}

When the mushy and liquid regions are modeled in the same domain as the solid (cf. discussion in section 2.4), they are often subjected to large displacements and strains arising from solidification shrinkage, buoyancy, or forced convection. Similar difficulties are generated in casting processes such as squeeze casting, where the entire domain is highly deformed. In these cases, a Lagrangian formulation would demand frequent remeshings in order to avoid mesh degeneracy, which is both computationally costly, and detrimental to the accuracy of the modeling. It is then preferable to use a so-called arbitrary Lagrangian Eulerian formulation (ALE). In an Eulerian formulation, material moves through the computational grid, which remains stationary in the "laboratory" frame of reference. In the ALE formulation, the updating of the mesh is partially independent of the velocity of the material particles in order to maintain the quality of the computational grid. Several methods can be used, including the popular "barycentering" technique which keeps each node at the geometrical centroid of a set of its neighbors. This method involves significant extra complexity to account for the advection of material through the domain, and the state variables such as temperature and inelastic strain must be updated according to the relative velocity between the mesh and the particles. In doing this, some surface constraints must be enforced in order to ensure mass conservation, expressing that the fluxes of mesh velocity and of fluid particle velocity through the surface of the mesh should remain identical. A review on the ALE method in solidification modeling is available, together with some details on its application. ${ }^{48}$

\subsection{Thermomechanical coupling}

Because of the interdependency between the thermal and mechanical analyses, as presented in section 3 , their coupling should be taken into account all during the cooling process. In practice, the cooling time is decomposed into time increments, each increment requiring the solution of two problems: the energy conservation and the momentum conservation. With the highly nonlinear elastic-visco-plastic constitutive equations typical of solidifying metals, the incremental steps required for the mechanical analysis to converge are generally much smaller than those for the thermal analysis. Thus, these two analyses are generally performed in succession and only once per time increment. However, in the case of very rapid cooling, these solutions might be preferably performed together (including thermal and mechanical unknowns in a single set of non-linear equations), or else separate but iteratively until convergence at each time increment, otherwise the time step has to be dramatically reduced.

\section{$5 \quad$ Model Validation}

Model validation with both analytical solutions and experiments is a crucial step in any computational analysis and thermo-mechanical modeling is no exception. Weiner and Boley ${ }^{6}$ derived an analytical solution for unidirectional solidification of an unconstrained plate with a unique solidification temperature, an elasticperfectly-plastic constitutive law and constant properties. The plate is subjected to sudden surface quench from a uniform initial temperature to a constant mold temperature.

This benchmark problem is ideal for the validation of computational thermal-stress models, as it can be solved with a one-dimensional mesh, as shown in Figure 2. Numerical predictions should match with arbitrary precision according to the mesh refinement. For example, the solidification stress analysis code, CON2D ${ }^{14}$ and the commercial code ABAQUS were applied for the conditions in Table $1 .^{44}$ The solidification temperature interval is spread over a small $\left(0.1{ }^{\circ} \mathrm{C}\right)$ artificial temperature range about the fusion temperature of $1494.4^{\circ} \mathrm{C}$. The instantaneous surface quench is modeled with high convection, $q_{\text {gap }}=h\left(T-T_{\infty}\right)$, to lessen the instabilities caused by these extreme conditions. The elastic-perfectly-plastic constitutive equation with $\sigma_{0}(\mathrm{MPa})=0.03+20\left(1494.4^{\circ} \mathrm{C}-\mathrm{T}\right) / 494.4$ was transformed to a numerically challenging rate formulation with the form of Eq. (5c), by setting $m=1$ and $K=6.67 \times 10^{-9} \mathrm{MPa}-\mathrm{s} .{ }^{44}$ This represents a limit case for this elastic-visco-plastic expression. To model the unconstrained plate with a 
BG Thomas and M. Bellet, ASM Handbook, Chap 15, S. Viswanathan ed., submitted October, 2006 single row of elements, a generalized plane strain condition was imposed in the $\mathrm{y}$ and $\mathrm{z}$ directions (parallel to the surface) by coupling the displacements of all nodes along the edges of the slice domain as shown in Figure $2 .{ }^{44}$ The constant axial strain assumed under this condition is computed by satisfying a single extra scalar equation:

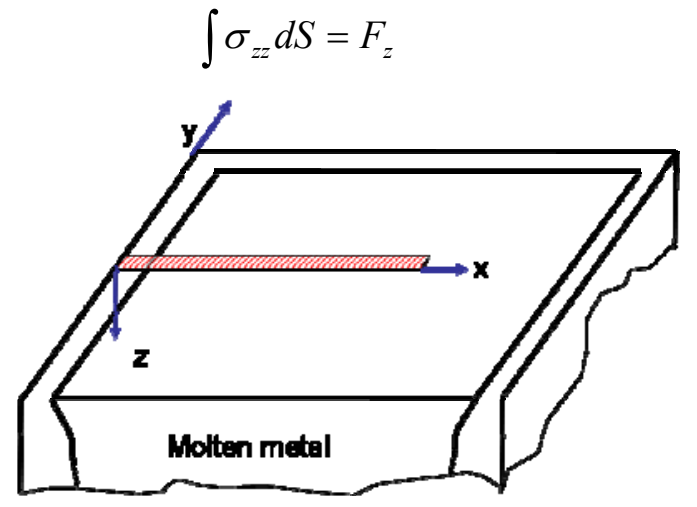

Figure 2. One-dimensional slice-domain for modeling solidifying plate.

Figure 3 and Figure 4 compare the temperature and stress profiles in the plate at two times. The temperature profile through the solidifying shell is almost linear. Because the interior cools relative to the fixed surface temperature, its shrinkage generates internal tensile stress, which induces compressive stress at the surface. With no applied external pressure, the average stress through the thickness must naturally equal zero, and stress must decrease to zero in the liquid. Stresses and strains in both transverse directions are equal for this symmetrical problem. The close agreement demonstrates that both computational models are numerically consistent and have an acceptable mesh resolution. Comparison with experimental measurements is also required, to validate that the modeling assumptions and input data are reasonable. 
BG Thomas and M. Bellet, ASM Handbook, Chap 15, S. Viswanathan ed., submitted October, 2006 Table 1. Constants used in solidification test problem.

\begin{tabular}{|l|l|}
\hline Conductivity, $k \quad\left[\mathrm{~W} \mathrm{~m}^{-1} \mathrm{~K}^{-1}\right]$ & 33.0 \\
\hline Specific Heat, $\mathrm{C}_{\mathrm{p}}\left[\mathrm{J} \mathrm{kg}^{-1} \mathrm{~K}^{-1}\right]$ & 661.0 \\
\hline Elastic Modulus in Solid, $E_{s}[\mathrm{GPa}]$ & 40.0 \\
\hline Elastic Modulus in Liquid, $E_{l}[\mathrm{GPa}]$ & 14.0 \\
\hline Thermal Linear Expansion Coefficient $\left[\mathrm{K}^{-1}\right]$ & 0.00002 \\
\hline Density, $\rho\left[\mathrm{kg} \mathrm{m}^{-3}\right]$ & 7500 \\
\hline Poisson's Ratio, $v$ & 0.3 \\
\hline Liquidus Temperature, $T_{L}\left[{ }^{\circ} \mathrm{C}\right]$ & 1494.45 \\
\hline Fusion Temperature $($ analytical$), T_{F}\left[{ }^{\circ} \mathrm{C}\right]$ & 1494.4 \\
\hline Solidus Temperature, $T_{S}\left[{ }^{\circ} \mathrm{C}\right]$ & 1494.35 \\
\hline Initial Temperature, $T_{0}\left[{ }^{\circ} \mathrm{C}\right]$ & 1495.0 \\
\hline Latent Heat, $L\left[\mathrm{~J} \mathrm{~kg}{ }^{-1} \mathrm{~K}^{-1}\right]$ & 272000 \\
\hline Liquid viscosity, $\mu_{l}[\mathrm{MPa}-\mathrm{sec}]$ & $2.22 \times 10^{-9}$ \\
\hline Surface Film Coefficient, $h\left[\mathrm{~W} \mathrm{~m}{ }^{-2} \mathrm{~K}^{-1}\right]$ & 250,000 \\
\hline Mold Temperature, $\mathrm{T}_{\infty}\left[{ }^{\circ} \mathrm{C}\right]$ & 1000 \\
\hline
\end{tabular}

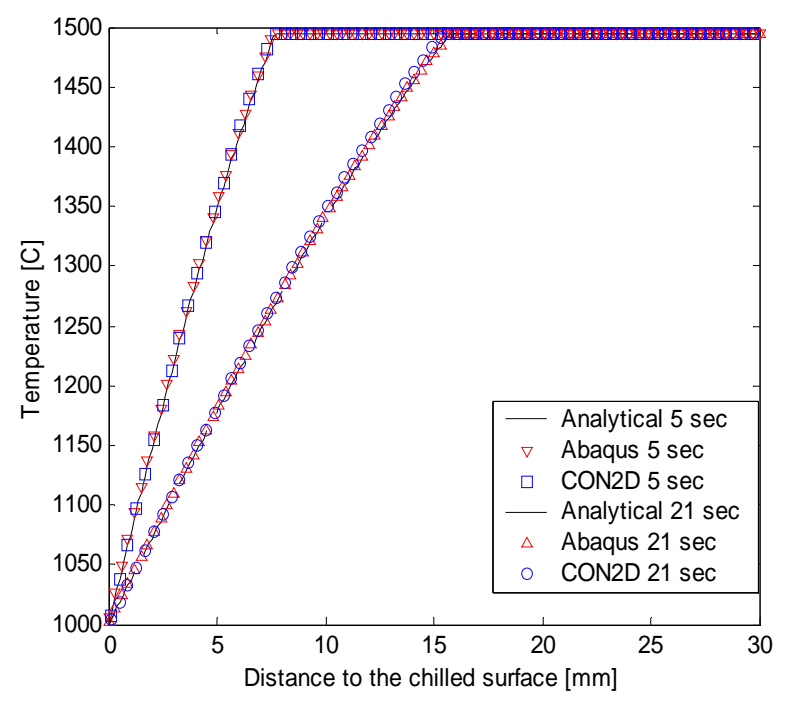

Figure 3. Temperatures through solidifying plate at different times comparing analytical solution and numerical predictions.

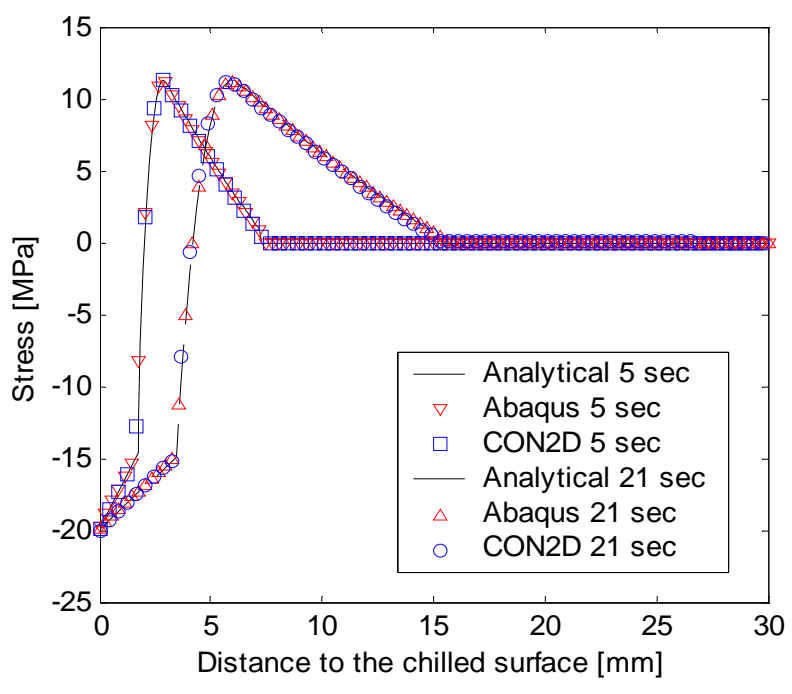


BG Thomas and M. Bellet, ASM Handbook, Chap 15, S. Viswanathan ed., submitted October, 2006 Figure 4. Transverse ( $Y$ and $Z$ ) stress through solidifying plate at different times comparing analytical solution and numerical predictions.

\section{Example Application: Mold Casting}

\subsection{Braking disks}

The finite element software THERCAST for thermomechanical analysis of solidification ${ }^{49}$ has been used in automotive industry to predict distortions of braking discs made of grey iron and cast in sand molds. ${ }^{50}$ A particular attention has been paid to the interaction between the deformation of internal sand cores and the cast parts. This demands a global coupled thermomechanical simulation, as presented above. Figure 5 illustrates the discretization of the different domains involved in the calculation. The actual cooling scenario has been simulated: cooling in mold during $45 \mathrm{~min}$, shake out and air cooling during $15 \mathrm{~min}$. Figure 6 gives the temperature evolution in different points located in a horizontal cross section at mid-height in the disc, showing the influence of different physical phenomena: solidification after $2 \mathrm{~min}$, solid state phase change after $20 \mathrm{~min}$. The deformation of the core has been calculated, bringing out the thermal buckling of core blades. They are exposed to very high temperature, and their dilatation is too much constrained, resulting in their deformation, as shown in Figure 7. This deformation causes a difference in thickness between the two braking tracks of the disc. Such a defect needs heavy and costly machining operations to get qualified parts. Instead, process simulation allows the manufacturer to test alternative geometries and process conditions in order to minimize the defect.

Similar thermomechanical calculations have been made in the case of plain discs, leading to comparisons with residual stress measurements by means of neutrons and X-ray diffraction. \{David, 2002 \#3720\} As shown in Figure 8, calculations are consistent with measurements, the difference being less than $10 \mathrm{MPa}$.
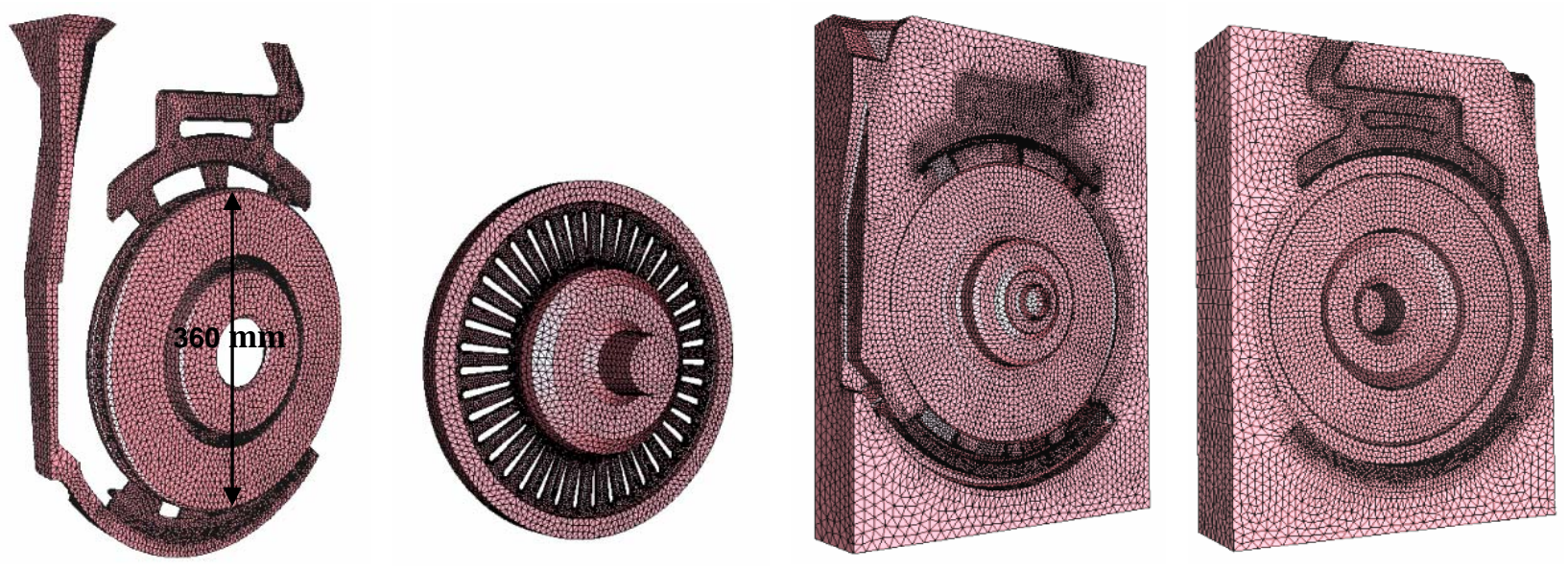

Figure 5. Finite element meshes of the different domains: part, core, and two half molds. 
BG Thomas and M. Bellet, ASM Handbook, Chap 15, S. Viswanathan ed., submitted October, 2006
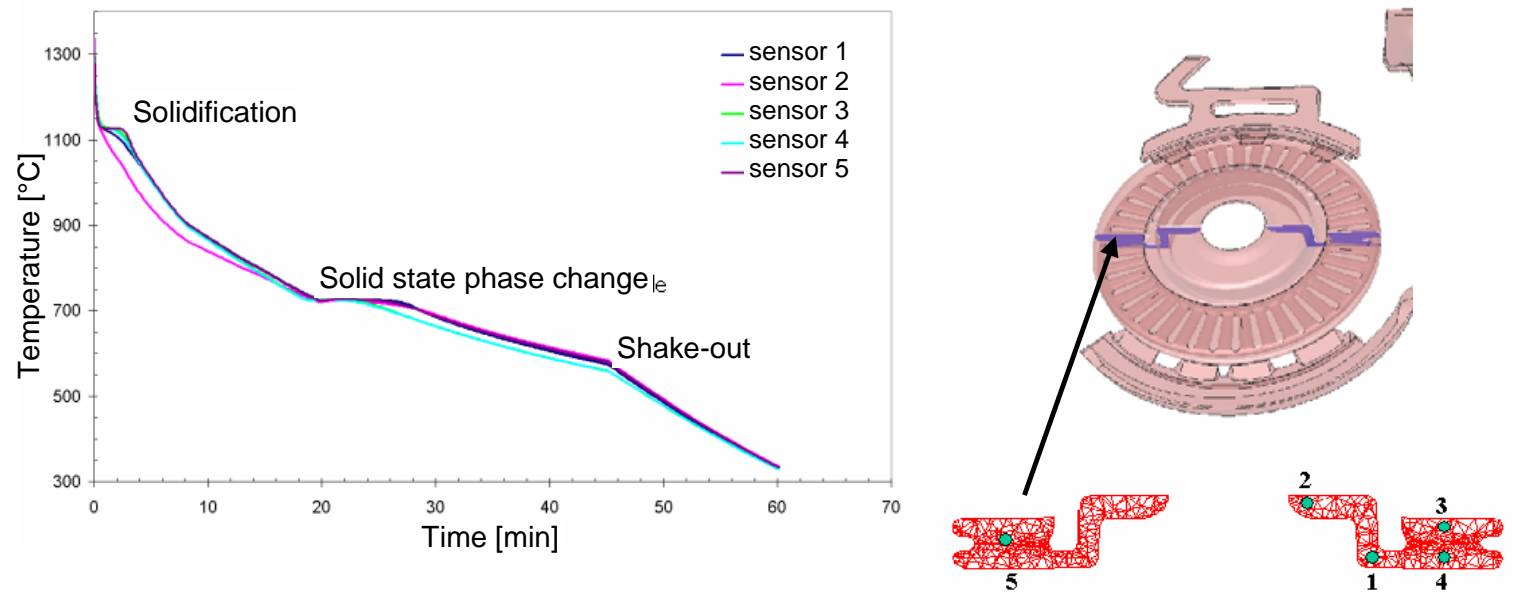

Figure 6. Temperature evolution in the part at different points located in the indicated section. 
BG Thomas and M. Bellet, ASM Handbook, Chap 15, S. Viswanathan ed., submitted October, 2006

Temperature $\left[{ }^{\circ} \mathrm{C}\right]$

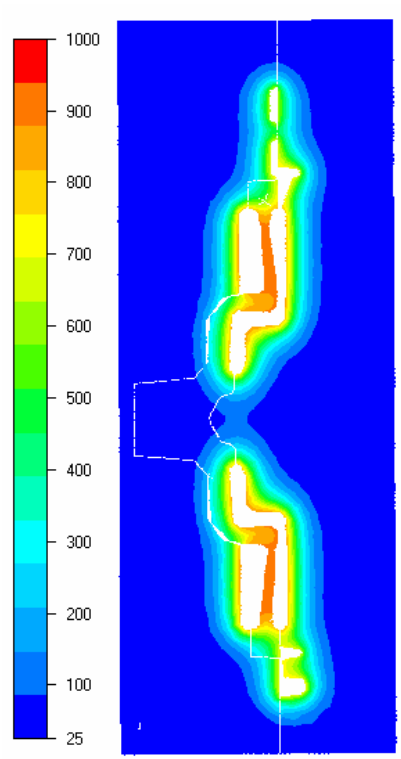

Vertical section

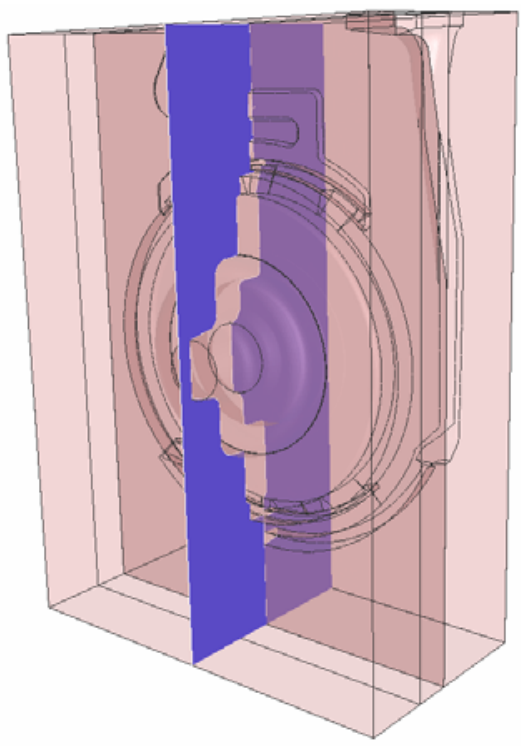

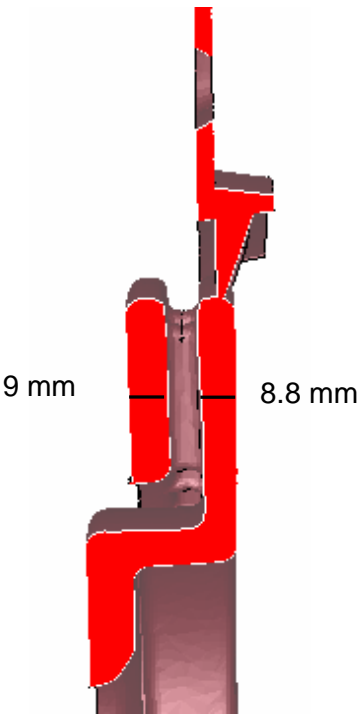

Figure 7. Deformation of core blades in a radial section, after a few seconds of cooling. On the left, displacements have been magnified by a factor 100 . The temperature distribution is superimposed. On the right, the difference in thickness between the two braking tracks is shown.
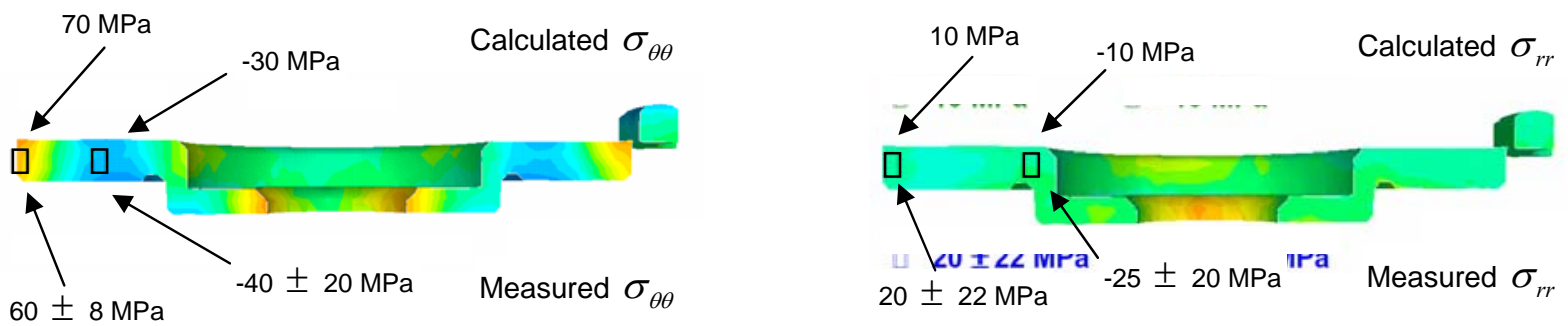

Figure 8. Residual hoop stresses (left) and radial stresses (right) in a radial section on as-cast plain discs made of grey iron. Top line: calculated values; bottom line: measured values.

\section{$7 \quad$ Hot tearing analysis}

Hot tearing is one of the most important consequences of stress during solidification. Hot tearing is caused by a combination of tensile stress and metallurgical embrittlement. It occurs at temperatures near the solidus when strain concentrates within the interdendritic liquid films, causing separation of the dendrites and intergranular cracks at very small strains (on the order of 1 percent). This complex phenomenon depends on the ability of liquid to flow through the dendritic structure to feed the volumetric shrinkage, the strength of the surrounding dendritic skeleton, the grain size and shape, the nucleation of supersaturated gas into pores or crack surfaces, the segregation of solute impurities, and the formation of interfering solid precipitates. The subsequent refilling of hot tears with segregated liquid alloy can cause internal defects that are just as serious as exposed surface cracks. The hot tearing of aluminum alloys is reviewed elsewhere. \{D.G. Eskin, 2004 \#3726\} Hot tearing phenomena are too complex and insufficiently understood to model in detail, so several different criteria have been developed to predict hot tears from the results of a thermal-mechanical analysis. 
BG Thomas and M. Bellet, ASM Handbook, Chap 15, S. Viswanathan ed., submitted October, 2006

Casting conditions that produce faster solidification and alloys with wider freezing ranges are more prone to hot tears. Thus, many criteria are solely based on thermal analysis. That of Clyne and Davies ${ }^{51}$ simply compares the local time spent between two critical solid fractions $g_{s 1}$ and $g_{s 2}$ (typically 0.9 and 0.99 , respectively), with the total local solidification time (or a reference solidification time). The "hot cracking susceptibility" is defined as:

$$
H C S_{\text {Clyne }}=\frac{t_{0.99}-t_{0.90}}{t_{0.90}-t_{0.40}}
$$

Criteria based on classical mechanics often assume cracks will form when a critical stress is exceeded, and they are popular for predicting cracks at lower temperatures ${ }^{52-55}$. This critical stress depends greatly on the local temperature and strain rate. Its accuracy relies on measurements, such as the submerged split-chill tensile test for hot tearing. ${ }^{56-58}$

Measurements often correlate hot tear formation with the accumulation of a critical level of mechanical strain while applying tensile loading within a critical solid fraction where liquid feeding is difficult. This has formed the basis for many hot-tearing criteria. That of Yamanaka et al. ${ }^{59}$ accumulates inelastic deformation over a brittleness temperature range, which is defined, for example as $g_{s} \in[0.85,0.99]$ for a Fe- $0.15 \mathrm{wt} \% \mathrm{C}$ steel grade. The local condition for fracture initiation is then:

$$
\sum_{g_{s 1}}^{g_{s 2}} \Delta \varepsilon_{i n} \geq \varepsilon_{c r}
$$

in which the critical strain $\varepsilon_{c r}$ is $1.6 \%$ at a typical strain rate of $3 \times 10^{-4} \mathrm{~s}^{-1}$. Careful measurements during bending of solidifying steel ingots have revealed critical strains ranging from 1 to $3.8 \%{ }^{59,60}$ The lowest values were found at high strain rate and in crack-sensitive grades (e.g. high-sulfur peritectic steel). ${ }^{59}$ In aluminum rich $\mathrm{Al}-\mathrm{Cu}$ alloys, critical strains were reported from 0.09 to $1.6 \%$ and were relatively independent of strain rate. ${ }^{61}$ Tensile stress is also a requirement for hot tear formation. ${ }^{59}$ The maximum tensile stress occurs just before formation of a critical flaw. ${ }^{61}$

The critical strain decreases with increasing strain rate, presumably because less time is available for liquid feeding, and also decreases for alloys with wider freezing ranges. Won et $\mathrm{a}^{62}$ suggested the following empirical equation for the critical strain in steel, based on fitting measurements from many bend tests:

$$
\varepsilon_{c r}=\frac{0.02821}{\dot{\varepsilon}^{0.3131} \Delta T_{B}^{0.8638}}
$$

where $\dot{\varepsilon}$ is the strain rate and $\Delta T_{B}$ is the brittle temperature range, defined between the temperatures corresponding to solid fractions of 0.9 and 0.99 .

More mechanistically-based hot-tearing criteria include more of the local physical phenomena that give rise to hot tears. Feurer, ${ }^{63}$ and more recently Rappaz et al. ${ }^{64}$ have proposed that hot tears form when the local interdendritic liquid feeding rate is not sufficient to balance the rate of tensile strain increase across the mushy zone. The criterion of Rappaz et al. predicts fracture when the strain rate exceeds a limit value that allows pore cavitation to separate the residual liquid film between the dendrites:

$$
\dot{\varepsilon} \geq \frac{1}{R}\left[\frac{\lambda_{2}^{2}\|\nabla T\|}{180 \mu_{l}} \frac{\rho_{L}}{\rho_{S}}\left(p_{m}-p_{C}\right)-v_{T} \frac{\rho_{S}-\rho_{L}}{\rho_{S}} H\right]
$$

in which $\lambda_{2}$ is the secondary dendrite arm spacing, $p_{m}$ is the local pressure in the liquid ahead of the mushy zone, $p_{C}$ is the cavitation pressure, $v_{T}$ is the velocity of the solidification front. The quantities $R$ and $H$ depend on the solidification path of the alloy:

$$
R=\frac{1}{\|\nabla T\|} \int_{T_{2}}^{T_{1}} \frac{g_{s}{ }^{2} F(T)}{g_{l}{ }^{3}} d T \quad H=\int_{T_{2}}^{T_{1}} \frac{g_{s}{ }^{2}}{g_{l}{ }^{2}} d T \quad F(T)=\frac{1}{\Delta T} \int_{T_{2}}^{T} g_{s} d T
$$


BG Thomas and M. Bellet, ASM Handbook, Chap 15, S. Viswanathan ed., submitted October, 2006 where the integration limits are calibration parameters which also have physical meaning. ${ }^{65}$ The upper limit $T_{1}$ may be the liquidus or the coherency temperature, while the lower limit $T_{2}$ typically is within the solid fraction range of $0.95-0.99 .^{66}$

\section{Application: Continuous Casting of Steel, Primary Cooling in Mold}

The two-dimensional transient finite-element thermal-mechanical model, CON2D ${ }^{14,}{ }^{44}$ has been applied to predict temperature, displacement, strain, stress and hot tearing during primary cooling in continuous casting of steel. This Lagrangian model tracks a transverse slice through the strand as it moves downwards at the casting speed to reveal the entire 3-D stress state. The 2-D assumption produces reasonable temperature predictions because axial (z-direction) conduction is negligible relative to axial advection. ${ }^{35}$ In-plane mechanical predictions should be reasonable because bulging effects are small and the undiscretized casting direction is modeled with the appropriate condition of generalized plain strain.

The mechanical properties of steel used with this model were discussed in Section 2.5, and feature temperature-dependent elastic modulus and composition-dependent elastic-viscoplastic constitutive behavior and density. Two specific example applications with this model are presented next: 1) predicting the ideal taper of the mold to minimize gap formation during slab casting and 2) finding the critical casting speeds to avoid quality problems related to bulging below the mold.

\subsection{Ideal Taper of a Slab Casting Mold}

Thermal and mechanical behavior were simulated in a slice through the centerline of the wide face of the solidifying steel shell (Figure 2), as it moves down through the continuous casting mold. The total shrinkage strain predicted for this slice has been shown to provide an accurate and economical estimate of the ideal taper that should be applied to the narrow faces of the mold, in order to avoid formation of an air gap. The corner effects are reasonably small and were ignored in this analysis. The total heat flux (integrated from the heat flux profile) was forced to match an empirical equation that was obtained from a curve fit of many measurements under different conditions at a typical slab caster. ${ }^{67}$ Computing ideal taper is useful application of computational models, in order to minimize the problems associated with excessive air gap formation, or pressure on defect formation and productivity.

Sample results are given in Figure 9 to Figure 12 for a typical $200 \mathrm{~mm}$ thick slab mold, based on standard conditions of $1000 \mathrm{~mm}$ width, $800 \mathrm{~mm}$ working mold length, and $1.5 \mathrm{~m} / \mathrm{min}$ casting speed. These figures show the effect of steel grade on heat flux, shell thickness, surface temperature, and ideal narrowface taper, all as a function of distance down the mold wall. Taper is presented as $\% /$ mold. A mold flux with $1215^{\circ} \mathrm{C}$ solidification temperature was assumed for the $0.13 \% \mathrm{C}$ peritectic steel and a $1120^{\circ} \mathrm{C}$ mold flux for the low and high carbon steels, which is typical of industrial practice. The practice of adopting mold powders with high solidification temperature and low viscosity was proposed by Wolf to produce lower, but more uniform heat transfer rates to help avoid cracks in depression-sensitive grades, such as peritectic steels. ${ }^{68}$ Slags with opposite properties are used for low and high carbon steels, to help avoid sticker problems.

The results show that the higher solidification-temperature mold flux, combined with the rougher shell surface produce a lower heat flux for the peritectic steel (Figure 9). The lower heat flux produces a thinner shell (Figure 10). It also produces a hotter shell surface temperature (Figure 11). This effect appears to outweigh the importance of the extra shrinkage of the peritectic steels. Thus, peritectic steels experience less shrinkage and require less taper than either low or high carbon steels (Figure 12).

The low carbon steel $(0.07 \% \mathrm{C})$ experiences more inelastic strain than other grades, owing to its microstructure being mainly composed of soft, delta phase. The delta-ferrite phase creeps faster than the stronger austenite phase found in other steels. The extra creep generated in the compressive solid surface 
BG Thomas and M. Bellet, ASM Handbook, Chap 15, S. Viswanathan ed., submitted October, 2006 layer tends to allow the interior shrinkage to have more effect in this grade. The net effect is that low carbon steel experiences a thicker shell with more shell shrinkage and taper than for the other grades.

As for every case studied in this work, significantly more mold taper is needed just below the meniscus than near mold exit. Thermal shrinkage strain dominates the need for taper. However, before implementing new taper designs into an operating casting mold, these results must be modified to account for several phenomena which affect ideal taper. These include the thermal distortion of the narrow face, relative to its distortion at the meniscus, the expansion and thermal distortion of the wide face, the decrease in wide face perimeter due to the change in mold cavity dimensions down a funnel mold, and finally, the variation in thickness of the resolidified mold flux layers down the mold. More details are provided by Thomas and Ojeda, ${ }^{69}$ but clearly, more work is needed before the model results can be safely used in practice.

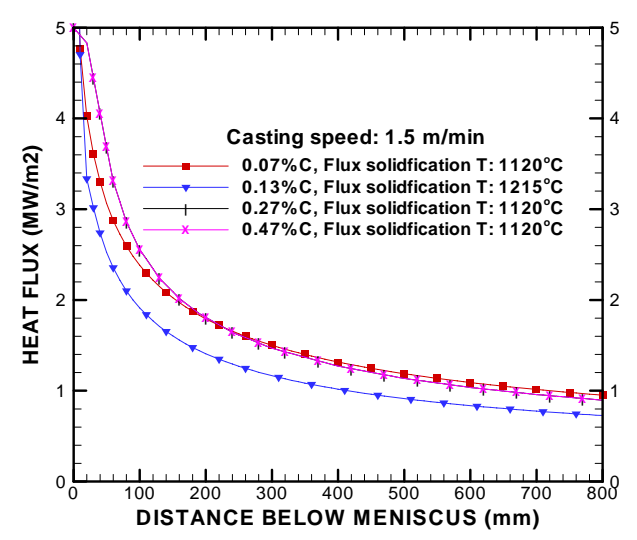

Figure 9. Heat flux profiles for different steel grades.

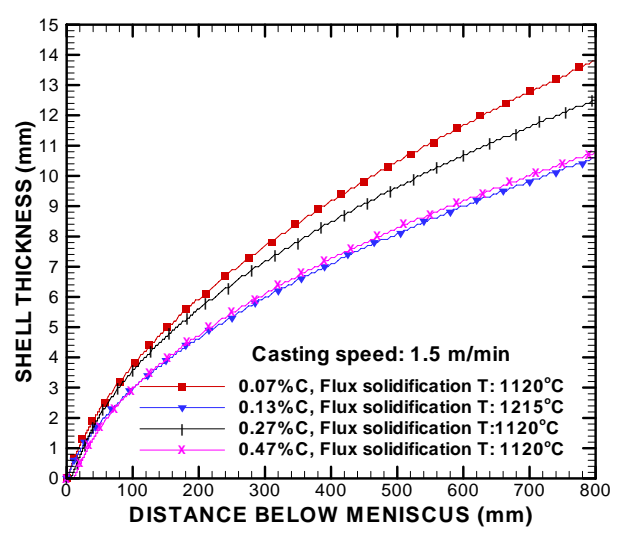

Figure 10. Shell thickness for different steel grades. 
BG Thomas and M. Bellet, ASM Handbook, Chap 15, S. Viswanathan ed., submitted October, 2006

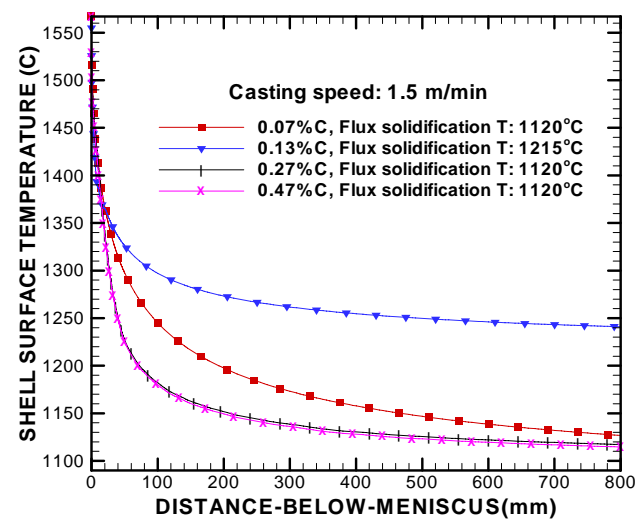

Figure 11. Shell surface temperature for different steel grades.

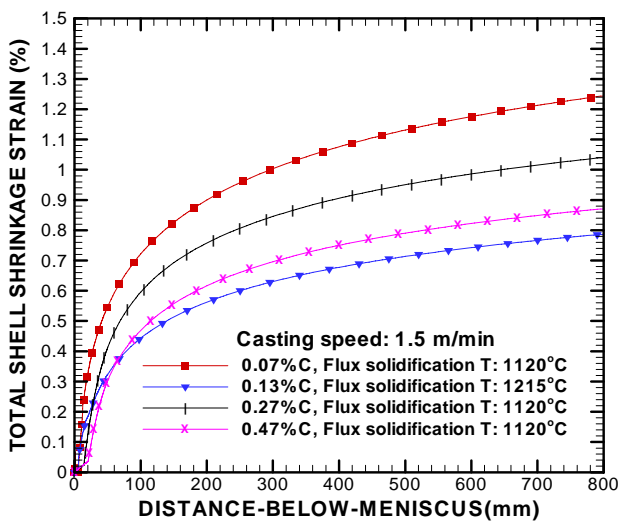

Figure 12. Total shell shrinkage strain for different steel grades.

\subsection{Maximum Casting Speed to Avoid Hot Tears in Billet Casting}

The model was next applied to predict the maximum casting speed allowable, while avoiding excessive bulging and hot tearing. Simulations start at the meniscus, $100 \mathrm{~mm}$ below the top of the mold, and extend through the 800-mm long mold and below, for a caster with no sub-mould support.

The model domain is an L-shaped region of a 2-D transverse section, shown in Figure 13. Removing the center portion of the section, which is always liquid, saves computational cost and allows a pressure boundary condition that avoids stability problems related to element "locking" that may occur with fixeddisplacement boundary conditions.

The instantaneous heat flux, given in Eq. (23), was based on fitting many plant measurements of total mold heat flux and differentiating. ${ }^{28}$ It was assumed to be uniform around the perimeter of the billet surface in order to simulate ideal taper and perfect contact between the shell and mold. Below the mold, the billet surface temperature was kept constant at its circumferential profile at mold exit. This eliminates the effect of spray cooling practice imperfections on sub-mold reheating or cooling and the associated complication for the stress/strain development. A typical plain carbon steel was studied $(0.27 \% \mathrm{c}, 1.52 \% \mathrm{Mn}, 0.34 \% \mathrm{Si})$ with $1500.7^{\circ} \mathrm{C}$ liquidus temperature, and $1411.8^{\circ} \mathrm{C}$ solidus temperature. 
BG Thomas and M. Bellet, ASM Handbook, Chap 15, S. Viswanathan ed., submitted October, 2006

$$
q\left(M W / m^{2}\right)= \begin{cases}5-0.2444 t(\mathrm{sec} .) & t \leq 1.0 \mathrm{sec} . \\ 4.7556 t(\mathrm{sec} .)^{-0.504} & t>1.0 \mathrm{sec} .\end{cases}
$$

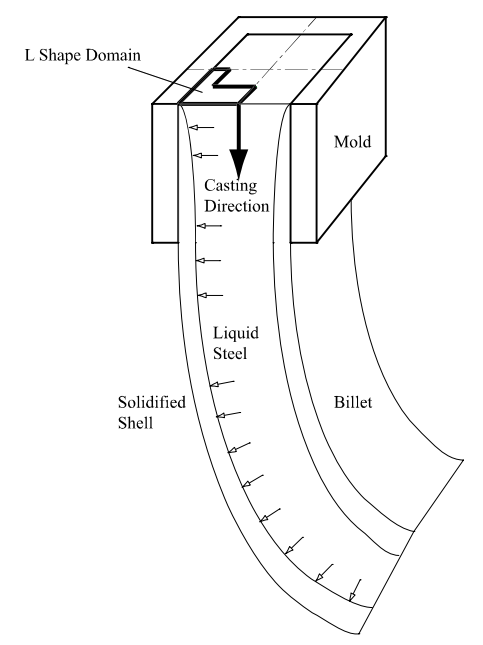

Figure 13. Model domain.

Simulation results are presented here for one-quarter of a $120 \mathrm{~mm}$ square billet cast at speeds of 2.0 and $5.0 \mathrm{~m} / \mathrm{min}$. The latter is the critical speed at which hot-tear crack failure of the shell is just predicted to occur.

The temperature and axial (z) stress distributions in a typical section through the wideface of the steel shell cast at $2.0 \mathrm{~m} / \mathrm{min}$ are shown in Figure 14 and Figure 15 at four different times during cooling in the mold. Unlike the analytical solution in Figure 3, the surface temperature drops as time progresses. The corresponding stress distributions are qualitatively similar to the analytical solution (Figure 4). The stresses increase with time, however, as solidification progresses. The realistic constitutive equations produce a large region of tension near the solidification front. The magnitude of these stresses (and the corresponding strains) are not enough to cause hot tearing in the mold, however.

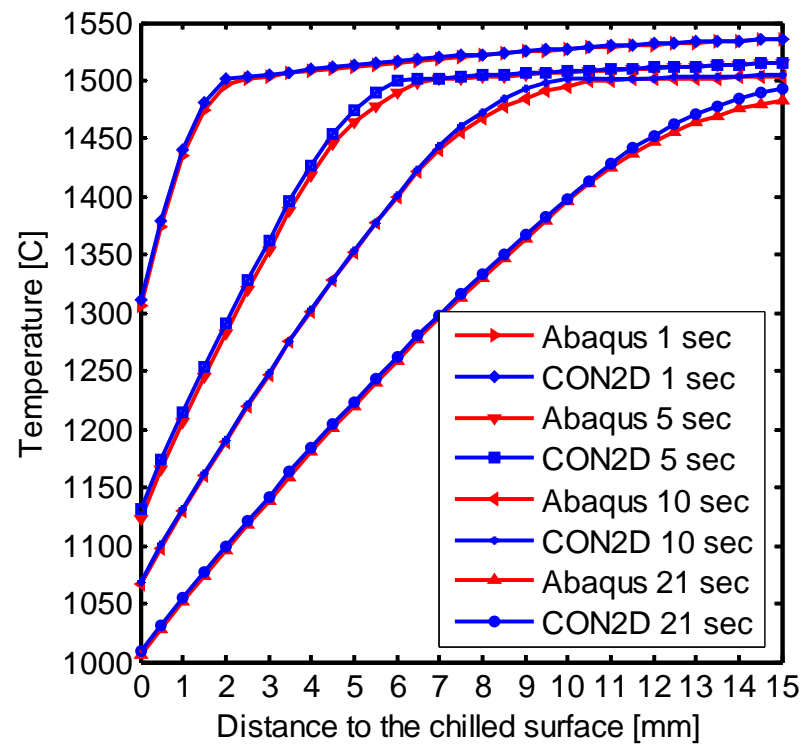

Figure 14. Temperature distribution along the solidifying slice in continuous casting mold. 
BG Thomas and M. Bellet, ASM Handbook, Chap 15, S. Viswanathan ed., submitted October, 2006

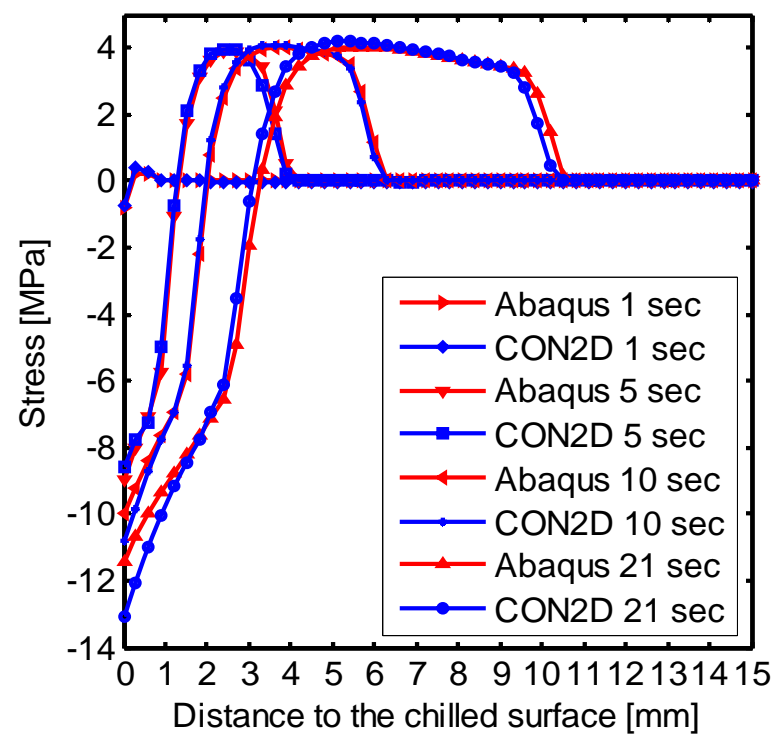

Figure 15. Lateral ( $y$ and $z$ ) stress distribution along the solidifying slice in continuous casting mold.

Figure 16(a) shows the distorted temperature contours near the strand corner at $200 \mathrm{~mm}$ below the mold exit, for a casting speed of $5.0 \mathrm{~m} / \mathrm{min}$. The corner region is coldest, owing to two-dimensional cooling. The shell becomes hotter and thinner with increasing casting speed, owing to less time in the mold. This weakens the shell, allowing it to bulge more under the ferrostatic pressure below the mold.

Figure 16(b) shows contours of "hoop" stress constructed by taking components in the x direction across the dendrites in the horizontal portion of the domain and the y direction in the vertical portion. High values appear at the off-corner sub-surface region, due to a hinging effect that the ferrostatic pressure over the entire face exerts around the corner. This bends the shell around the corner and generates high subsurface tensile stress at the weak solidification front in the off-corner subsurface location. This tensile stress peak increases slightly and moves towards the surface at higher casting speed. Stress concentration is less and the surface hoop stress is compressive at the lower casting speed. This indicates no possibility of surface cracking. However, tensile surface hoop stress is generated below the mold at high speed in Figure 16(b) at the face center due to excessive bulging. This tensile stress, and the accompanying hot-tear strain, might contribute to longitudinal cracks which penetrate the surface.

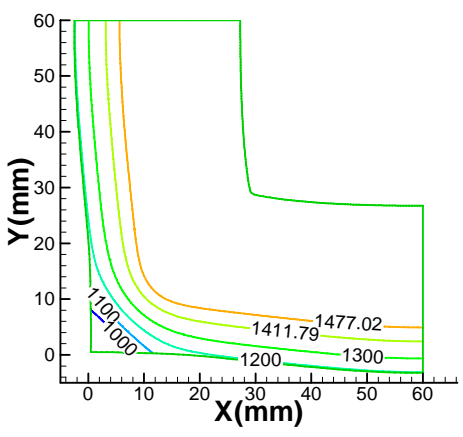

(a) Temperature

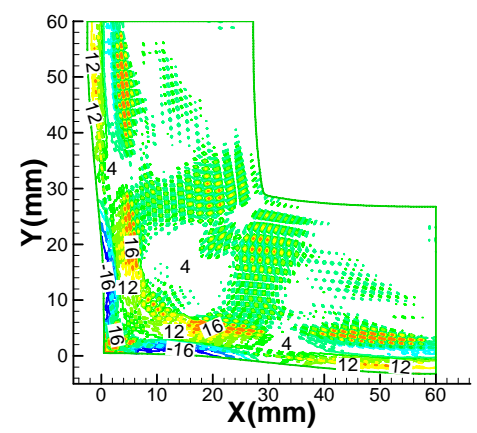

(b) Hoop stress

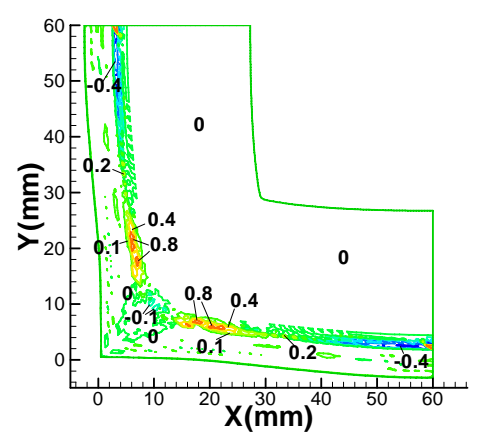

(c) Hot-tear strain

Figure 16. Distorted contours at $200 \mathrm{~mm}$ below mold exit.

Hot tearing was predicted using the criterion in Eq. (19) with the critical strain given in Eq. (20), and critical temperatures in Error! Reference source not found.. Inelastic strain was accumulated for the component oriented normal to the dendrite growth direction, because that is the weakest direction and corresponds to the measurements used to obtain Eq. (20). Figure 16(c) shows contours of hot-tear strain in 
BG Thomas and M. Bellet, ASM Handbook, Chap 15, S. Viswanathan ed., submitted October, 2006 the hoop direction. The highest values appear at the off-corner sub-surface region in the hoop direction. Moreover, significantly higher values are found at higher casting speeds. For this particular example, hottear strain exceeds the threshold at 12 nodes, all located near the off-corner subsurface region. This is caused by the hinging mechanism around the corner. No nodes fail at the center surface, in spite of the high tensile stress there. The predicted hot-tearing region matches the location of off-corner longitudinal cracks observed in sections through real solidifying shells, such as the one pictured in Figure 17. The bulged shape is also similar.

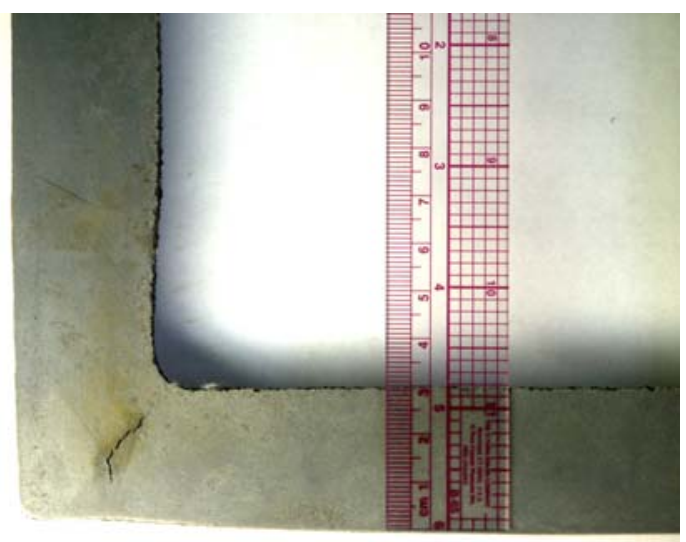

Figure 17. Off-corner internal crack in break-out shell from a $175 \mathrm{~mm}$ square bloom.

Results from many computations were used to find the critical speed to avoid hot tear cracks as a function of section size and working mold length, presented in Figure $18 .^{70}$ These predictions slightly exceed plant practice, which is generally chosen by empirical trial and error. This suggests that plant conditions such as mold taper are less than ideal, that other factors limit casting speed, or those speeds in practice could be increased. The qualitative trends are the same.

This quantitative model of hot tearing has enabled many useful insights into the continuous casting process. Larger section sizes are more susceptible to bending around the corner, so have a lower critical speed, resulting in less productivity increase than expected. The trend towards longer molds over the past three decades enables a higher casting speed without cracks by producing a thicker, stronger shell at mold exit.

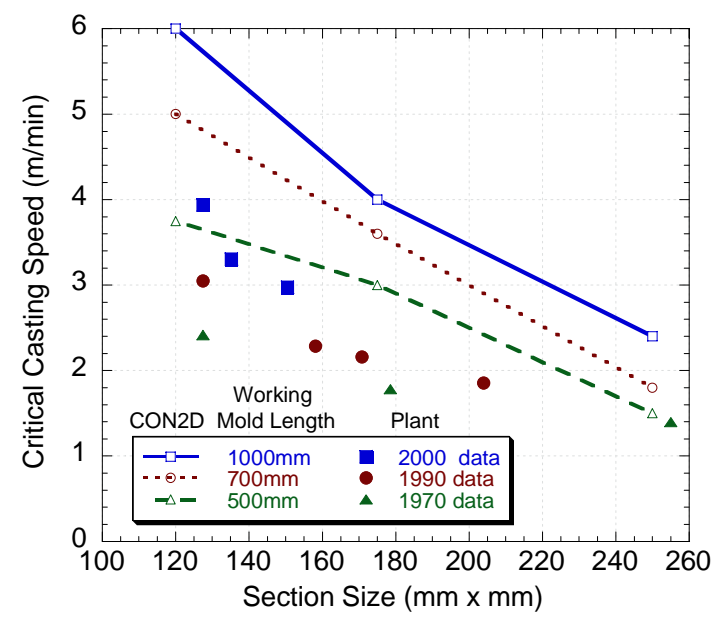

Figure 18. Comparison of critical casting speeds, based on hot-tearing criterion, and typical plant practice ${ }^{71}$

\section{$9 \quad$ Application: Continuous Casting of Steel, Secondary Cooling}


BG Thomas and M. Bellet, ASM Handbook, Chap 15, S. Viswanathan ed., submitted October, 2006

Thermomechanical simulations are used by steelmakers to analyze stresses and strains all along the secondary cooling zone. One of their thrust is the prediction the bulging of the solidified crust between the supporting rolls which is responsible for the tensile stress state in the mushy core, which in turn induces central macrosegregations ${ }^{72,}$. 73 wo and three-dimensional finite element models have been recently developed, based on an original "global non steady-state" approach which provides results on the whole length of the caster. The approach implemented in THERCAST software is described in detail elsewhere. ${ }^{23}$ 74 The constitutive models are those presented in section 2 . The contact with supporting rolls is controlled by a penalty formulation derived from what has been presented in section 4.3 , using penalty coefficients attached to the different rolls and continuously adapted in order to control the numerical penetration of the strand. Figure 19 shows the results obtained on a vertical-curved machine (strand thickness $0.22 \mathrm{~m}$, casting speed $0.9 \mathrm{~m} / \mathrm{min}$, material $\mathrm{Fe}-0.06 \mathrm{wt} \% \mathrm{C}$ ) in a region located around $11 \mathrm{~m}$ below the meniscus. The pressure distribution reveals a double alternation of compressive and depressive zones. First, along the strand surface, the material is in a compressive state under rolls where the pressure reaches its maximum, $36 \mathrm{MPa}$. Conversely, it is in a depressive (tensile) state between rolls, where the pressure is minimum (-9 MPa). Examination of the pressure state within the solid shell close to the solidification front (i.e. close to the solidus isotherm), reveals that the stress alternates. The steel is in a tensile state (negative pressure of about $-2 \mathrm{MPa}$ ) when passing in front of rolls, while it is in a compressive state in between, the value of pressure being around 2 to $3 \mathrm{MPa}$. These results agree with previous structural analyses of the deformation of the solidified shell between rolls, such as those carried out in static conditions by Wünnenberg, ${ }^{75}$ Miyazawa and Schwerdtfeger ${ }^{72}$ or by Kajitani et al. ${ }^{76}$ on limited slab sections moving downstream between rolls and submitted to the metallurgical pressure onto the solidification front. The influence of process parameters on the thermomechanical state of the strand can then be studied using such numerical models. An example is given by Figure 20, presenting the sensitivity of bulging to the casting speed. It can also be seen that bulging predictions are sensitive to the roll pitch, a larger pitch between two sets of rolls inducing an increased bulging. These numerical simulations can then be used to study possible modifications in the design of continuous casters, such as the replacement of large rolls by smaller ones in order to reduce the pitch and the associated bulging. ${ }^{77}$ 
BG Thomas and M. Bellet, ASM Handbook, Chap 15, S. Viswanathan ed., submitted October, 2006
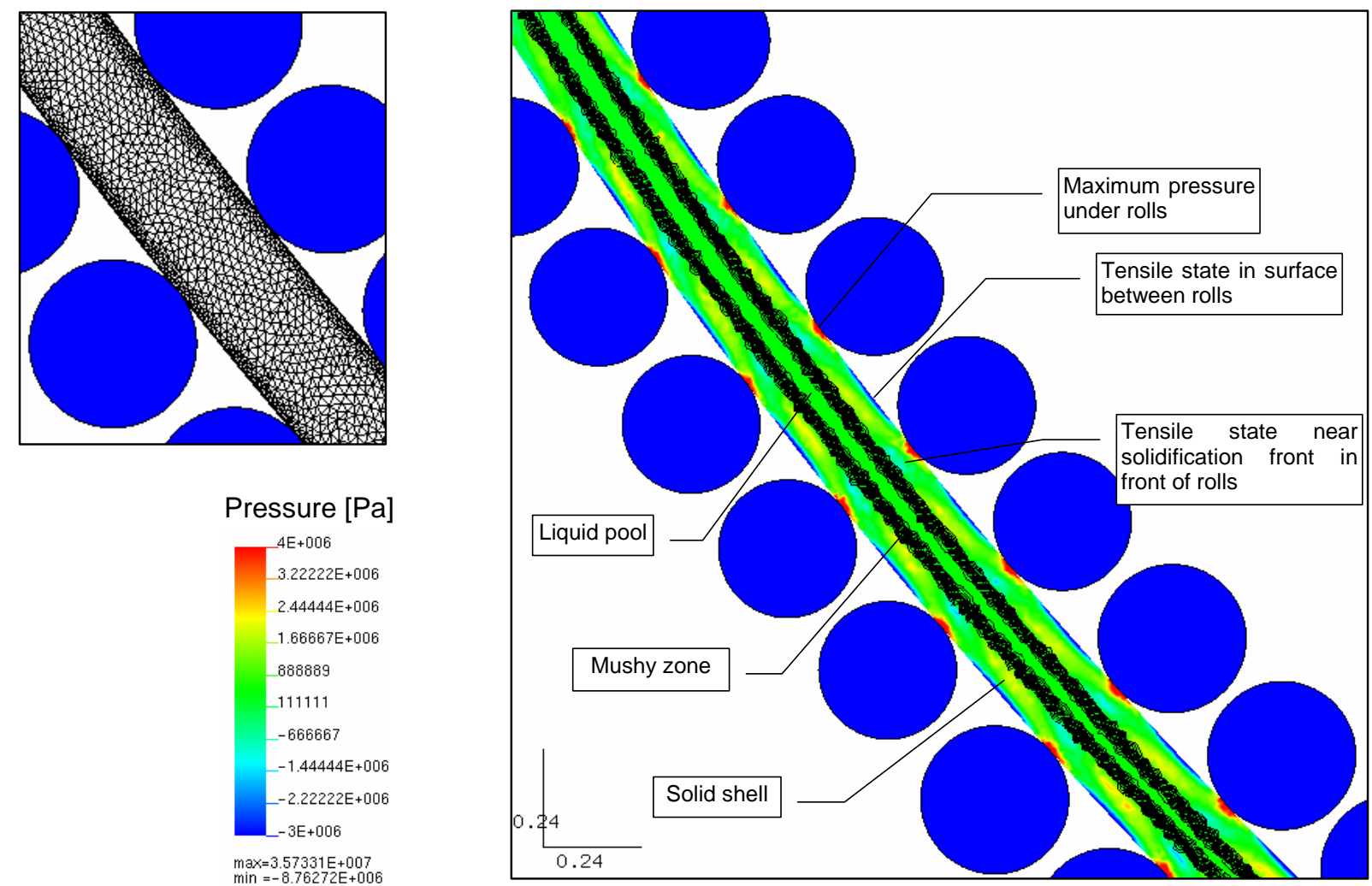

Figure 19. Illustration of the results of the calculations in the middle of the secondary cooling zone, at a metallurgical length of about $11 \mathrm{~m}$. On the top left view, the finite element mesh can be seen, with a fine band of $20 \mathrm{~mm}$. On the right view, the pressure distribution reveals compressive and depressive zones, the latter being close to the solidification front (the mushy zone is materialized by 20 lines separated by an interval $\left.\Delta g_{l}=0.05\right)$.

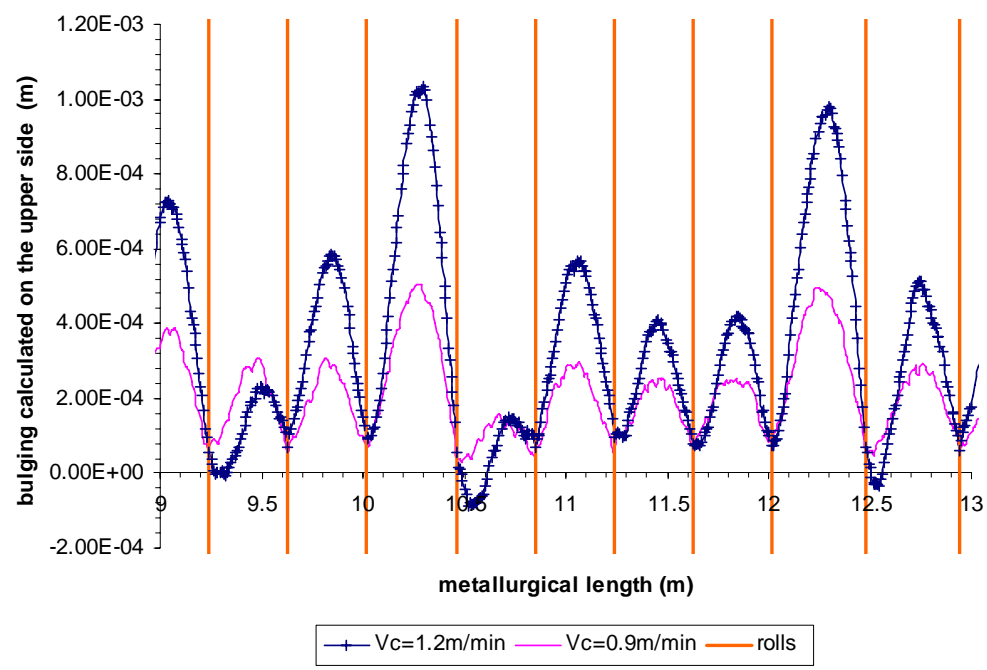

Figure 20. Slab bulging calculated at two different casting speed: $0.9 \mathrm{~m} / \mathrm{min}$ and $1.2 \mathrm{~m} / \mathrm{min}$. The slab bulging increases with the casting speed. ${ }^{77}$

\section{Conclusions}


BG Thomas and M. Bellet, ASM Handbook, Chap 15, S. Viswanathan ed., submitted October, 2006

Mechanical analysis of casting processes is growing in sophistication, accuracy, and phenomena incorporated. Quantitative predictions of temperature, deformation, strain, stress, and hot tearing in real casting processes are becoming possible. Computations are still hampered by the computational speed and limits of mesh resolution, especially for realistic three-dimensional geometries and defect analysis. Further developments are needed in fundamental models of defect formation over multiple length scales, and in efficient convergence algorithms to solve the equations. Fundamental measurements, including the quantification of interfacial conditions, material constitutive properties and conditions for defect formation are also needed. However, solidification processes are growing in maturity and improvements gained by trial and error in the plant are becoming more expensive. As computing power and software tools continue to advance, advanced computational models will become even more important in the years to come. Future advances to casting processes will increasingly rely on advanced computational models such as the thermomechanical models discussed here.

\section{Acknowledgements}

The authors wish to thank the Continuous Casting Consortium and the National Center for Supercomputing Applications at the University of Illinois, the French Ministry of Industry, the French Technical Center of Casting Industries (CTIF) and the companies Arcelor, Ascometal, Atlantic Industrie, Aubert et Duval, Erasteel, Industeel and PSA Peugeot-Citroën, for support of this work.

\section{References}

1. Thomas, B.G., Q. Yuan, S. Sivaramakrishnan, T. Shi, S.P. Vanka and M.B. Assar, Comparison of Four Methods to Evaluate Fluid Velocities in a Continuous Casting Mold, ISIJ Internat., 41, 10, (2001), 1266-1276.

2. Yuan, Q., B. Zhao, S.P. Vanka and B.G. Thomas, Study of Computational Issues in Simulation of Transient Flow in Continuous Casting, Steel Research International, 76, 1, Special Issue: Simulation of Fluid Flow in Metallurgy, (2005), 33-43.

3. Yuan, Q., S. Sivaramakrishnan, S.P. Vanka and B.G. Thomas, Computational and Experimental Study of Turbulent Flow in a 0.4-Scale Water Model of a Continuous Steel Caster, Metall. \& Mater. Trans., 35B, 5, (2004), 967-982.

4. Estrin, Y., A versatile unified constitutive model based on dislocation density evolution, in Constitutive modelling - Theory and Application, MD-vol26 / AMD-vol121, ASME, New York (1991), 65-75.

5. C. Agelet de Saracibar, M. Cervera and M. Chiumenti, On the constitutive modeling of coupled thermomechanical phase-change problems, Int. J. Plasticity, 17, (2001), 1565-1622.

6. Weiner, J.H. and B.A. Boley, Elasto-plastic thermal stresses in a solidifying body, J. Mech. Phys. Solids, 11, (1963), 145-154.

7. Smelser, R.E. and O. Richmond, Constitutive model effects on stresses and deformations in a solidifying circular cylinder, Modeling of Casting and Welding Processes IV, A.F. Giamei and G.J. Abbaschian, eds., Palm Coast, FL, The Minerals, Metals \& Materials Society, Warrendale, PA, (1988), 313-328.

8. M. Bellet, F. Decultieux, M. Ménaï, F. Bay, C. Levaillant, J.L. Chenot, P. Schmidt and I.L. Svensson, Thermomechanics of the cooling stage in casting processes: 3D finite element analysis and experimental validation, Metall. Trans. B, 27, (1996), 81-1000.

9. Fjaer, H.G. and A. Mo, ALSPEN - A mathematical model for thermal stresses in DC-cast Al billets, Metall. Trans., 21B, 6, (1990), 1049-1061.

10. J.W. Wiese and J.A. Dantzig, Modelling stress development during the solidification of grey iron castings, Metall. Mater. Trans. A 21, (1990), 489-497.

11. T. Inoue and D.Y. Ju, Simulation of solidification and viscoplastic stresses during vertical semicontinuous direct chill casting of aluminium alloy, Int. J. Plasticity 8, (1992), 161-183. 
BG Thomas and M. Bellet, ASM Handbook, Chap 15, S. Viswanathan ed., submitted October, 2006

12. Moitra, A., B.G. Thomas and W. Storkman, Thermo-mechanical model of Steel Shell Behavior in the Continuous Casting Mold, in EPD Congress, Proceedings of TMS Annual Meeting, The Minerals, Metals, and Materials Society, Warrendale, PA, San Diego, CA, (1992), 547-577.

13. D. Celentano, S. Oller and E. Oñate, A finite element model for thermomechanical analysis in casting processes, Journal de Physique, 3, (1993), 1171-1180.

14. Li, C. and B.G. Thomas, Thermo-Mechanical Finite-Element Model of Shell Behavior in Continuous Casting of Steel, Metal. \& Material Trans. B., 35B, 6, (2004), 1151-172.

15. M.A. Cruchaga, D.J. Celentano and R.W. Lewis, Modeling fluid-solid thermomechanical interactions in casting processes, Int. J. Num. Meth. for Heat and Fluid Flow 14, (2004), 167-186.

16. M. Bellet, O. Jaouen and I. Poitrault, An ALE-FEM approach to the thermomechanics of solidification processes with application to the prediction of pipe shrinkage, Int. J. Num. Meth. Heat Fluid Flow, 15, (2005), 120-142.

17. L.C. Nicolli, A. Mo and M. M'Hamdi, Modeling of macrosegregation caused by volumetric deformation in a coherent mushy zone, Metall. Mater. Trans. A, 36, (2005), 433-442.

18. V.D. Fachinotti, S. Le Corre, N. Triolet, M. Bobadilla and M. Bellet, Two-phase thermo-mechanical and macrosegregation modelling of binary alloys solidification with emphasis on the secondary cooling stage of steel slab continuous casting, Int. J. Num. Meth. Eng., (2006), in press.

19. Kozlowski, P., B.G. Thomas, J. Azzi and H. Wang, Simple Constitutive Equations for Steel at High Temperature, Metall. Trans. A, 23A, 3, (1992), 903-918.

20. Wray, P.J., Plastic Deformation of Delta-Ferritic Iron at Intermediate Strain Rates, Metall. Trans. A, 7A, Nov., (1976), 1621-1627.

21. Wray, P.J., Effect of Carbon Content on the Plastic Flow of Plain Carbon Steels at Elevated Temperatures, Metall. Trans. A, 13A, 1, (1982), 125-134.

22. Suzuki, T., K.H. Tacke, K. Wunnenberg and K. Schwerdtfeger, Creep Properties of Steel at Continuous Casting Temperatures, Ironmaking Steelmaking, 15, 2, (1988), 90-100.

23. F. Costes, A. Heinrich and M. Bellet, 3D thermomechanical simulation of the secondary cooling zone of steel continuous casting, in Proc. MCWASP X, 10th Int. Conf. on Modeling of Casting, Welding and Advanced Solidification Processes, J.A.W. D.M. Stefanescu, M.R. Jolly \& M.J.M. Krane, ed. The Minerals, Metals \& Materials Society, Warrendale, Pennsylvania, USA, (2003), 393400 .

24. Donsbach, D.L. and M.W. Moyer, Ultrasonic Measurement of Elastic Constants at Temperatures from 20 to 1100 oC, in Ultrasonic Materials Characterization, Special Pub. 596, H. Berger and M. Linzer, eds., Nat. Bureau of Standards, (1980).

25. Puhringer, O.M., Strand Mechanics for Continuous Slab Casting Plants, Stahl Eisen, 96, 6, (1976), 279-284.

26. Hub, D.R., Measurement of Velocity and Attenuation of Sound in Iron up to the Melting Point, Proc. IVth Intern. Vong. Acoustics, Copenhagen, (1962), paper 551, paper \#551.

27. Mizukami, H., K. Murakami and Y. Miyashita, Mechanical Properties of Continuously Cast Steels at High Temperatures, Tetsu-to-Hagane, 63, 146, (1977), S 652.

28. Li, C. and B.G. Thomas, Maximum Casting Speed for Continuous Cast Steel Billets Based on SubMold Bulging Computation, in Steelmaking Conf. Proc., 85, ISS, Warrendale, PA, Nashville, TN, March 10-13, 2002, (2002), 109-130.

29. Li, C. and B.G. Thomas, Thermo-Mechanical Finite Element Model of Bulging and Hot Tearing During Continuous Casting of Steel Billets, in Modeling of Casting, Welding, and Advanced Solidification Processes, X, D. Stefanescu, J. Warren, M. Jolly and M. Krane, eds., TMS, Warrendale, PA, San Destin, FL, May 25-30, 2003, (2003), 385-392.

30. Harste, K., A. Jablonka and K. Schwerdtfeger, Shrinkage and Formation of Mechanical Stresses during Solidification of Round Steel Strands, 4th Int. Conf. on Continuous Casting, Centres de Recherches Metallurgiques and Verein Deutscher Eisenhuttenleute, Stahl und Eisen, Brussels, (1988), 633-644. 
BG Thomas and M. Bellet, ASM Handbook, Chap 15, S. Viswanathan ed., submitted October, 2006

31. Harste, K., Investigation of the shinkage and the origin of mechanical tension during the solidification and successive cooling of cylindrical bars of Fe-C alloys, PhD Dissertation Thesis, Technical University of Clausthal, (1989), not labelled.

32. Jimbo, I. and A. Cramb, The density of liquid iron-carbon alloys, Metall. Trans. B, 24B, (1993), 510 .

33. J. Kron, M. Bellet, A. Ludwig, B. Pustal, J. Wendt and H. Fredriksson, Comparison of numerical simulation models for predicting temperature in solidification analysis with reference to air gap formation, Int. J. Cast Metals Research, 17, (2004), 295-310.

34. Kelly, J.E., K.P. Michalek, T.G. O'Connor, B.G. Thomas and J.A. Dantzig, Initial Development of Thermal and Stress Fields in Continuously Cast Steel Billets, Metall. Trans. A, 19A, 10, (1988), 2589-2602.

35. Meng, Y. and B.G. Thomas, Heat Transfer and Solidification Model of Continuous Slab Casting: CON1D, Metal. \& Material Trans., 34B, 5, (2003), 685-705.

36. C.V. Madhusudana and L.S. Fletcher, Contact Heat Transfer - The last decade, , AIAA Journal, 24, (1985), 510-523.

37. G. Laschet, J. Jakumeit and S. Benke, Thermo-mechanical analysis of cast/mould interaction in casting processes, , Z. Metallkd, 95, (2004), 1087-1096.

38. M. Rappaz, M. Bellet and M. Deville, Numerical Modeling in Materials Science and Engineering, in Springer Series in Computational Mathematics, Springer-Verlag, Berlin, (2003).

39. Zienkiewicz, O.C. and R.L. Taylor, The Finite Element Method, fourth ed., McGraw Hill, New York, NY, (1988).

40. ABAQUS Theory Manual v6.0, Abaqus, Inc., Pawtucket, Rhode Island, (2004).

41. Nemat-Nasser, S. and Y.F. Li, An explicit Algorithm for large-strain, large-strain rate elasticviscoplasticity, Comp. Meths. Appl. Mech. Engng, 48, (1992), 205-219.

42. Lush, A.M., G. Weber and L. Anand, An Implicit Time-integration Procedure for A Set of Internal Variable Constitutive Equations for Isotropic Elastic-Viscoplasticity, Int. J. Plasticity, 5, (1989), 521-549.

43. Zhu, H., Coupled thermal-mechanical finite-element model with application to initial solidification, Thesis, University of Illinois, (1993).

44. Koric, S. and B.G. Thomas, Efficient Thermo-Mechanical Model for Solidification Processes, Int. J. Num. Meths. Eng., (2006), in press.

45. Glowinski, R. and P.L.Tallee, Augmented Lagrangian and Operator-Splitting Methods in Non-linear Mechanics, Studies in Applied Mathematics, SIAM, 9, (1989).

46. P. Wriggers and G. Zavarise, On contact between three-dimensional beams unergoing large deflections, , Comm. Num. Meth. Eng., 13, (1997), 429-438.

47. O. Jaouen and M. Bellet, A numerical mechanical coupling algorithm for deformable bodies: application to part/mold interaction in casting process, in Proc. 8th Int. Conf. on Modelling of Casting, Welding and Advanced Solidification Processes, B.G. Thomas and C. Beckermann, eds., The Minerals Metals and Materials Society, Warrendale, PA, San Diego (CA, USA), June 7-12, 1998, (1998), 739-746.

48. M. Bellet and V.D. Fachinotti, ALE method for solidification modelling, Comput. Methods Appl. Mech. and Engrg., 193, (2004), 4355-4381.

49. Thercast. presentation. www.transvalor.com and www.scconsultants.com. (2006),

50. Bellet, M., C. Aliaga and O. Jaouen, Finite elements for a thermomechanical analysis of solidification processes, in Modeling of Casting, Welding, and Advanced Solidification Processes $I X$, Shaker Verlag GmbH, Aachen, (2000), 10-17.

51. Clyne, T.W. and G.J. Davies, Comparison between experimental data and theorical predictions relating to dependence of solidification cracking on composition, in Solidification and Casting of Metals, The Metals Society, London, (1979), 275-278. 
BG Thomas and M. Bellet, ASM Handbook, Chap 15, S. Viswanathan ed., submitted October, 2006

52. Kinoshita, K., T. Emi and M. Kasai, Thermal Elasto-plastic Stress Analysis of Solidifying Shell in Continuous Casting Mold, Tetsu-to-Hagane, 65, 14, (1979), 2022-2031.

53. Kristiansson, J.O., Thermal stresses in the early stage of solidification of steel, J. Thermal Stresses, 5, (1982), 315-330.

54. Thomas, B.G., I.V. Samarasekera and J.K. Brimacombe, Mathematical Model of the Thermal Processing of Steel Ingots, Part II: Stress Model, Metall. Trans. B, 18B, 1, (1987), 131-147.

55. Okamura, K. and H. Kawashima, Calculation of Bulging Strain and its Application to Prediction of Internal Cracks in Continuously Cast Slabs, in Proc. Int. Conf. Comp. Ass. Mat. Design Proc. Simul., ISIJ, Tokyo, (1993), 129-134.

56. Ackermann, P., W. Kurz and W. Heinemann, In Situ Tensile Testing of Solidifying Aluminum and Al-Mg Shells, Materials Science and Engineering, 75, (1985), 79-86.

57. Bernhard, C., H. Hiebert and M.M. Wolf, Simulation of shell strength properties by the SSCT test, ISIJ International (Japan), 36, Suppl. Science and Technology of Steelmaking, (1996), S163-S166.

58. Suzuki, M., C. Yu and T. Emi, In-Situ Measurement of Tensile Strength of Solidifying Steel Shells to Predict Upper Limit of Casting Speed in Continuous Caster with Oscillating Mold, ISIJ International, Iron \& Steel Inst. of Japan, 37, 4, (1997), 375-382.

59. Yamanaka, A., K. Nakajima, K. Yasumoto, H. Kawashima and K. Nakai, Measurement of Critical Strain for Solidification Cracking, Modelling of Casting, Welding, and Advanced Solidification Processes - V, M. Rappaz, M.R. Ozgu and K.W. Mahin, eds., Davos, SW, TMS, Warrendale, PA, V, (1990), 279-284.

60. Yamanaka, A., K. Nakajima and K. Okamura, Critical Strain for Internal Crack Formation in Continuous Casting, Ironmaking Steelmaking, 22, 6, (1995), 508-512.

61. Wisniewski, P. and H.D. Brody, Tensile Behavior of Solidifying Aluminum Alloys, Modelling of Casting, Welding, and Advanced Solidification Processes - V, M. Rappaz, M.R. Ozgu and K.W. Mahin, eds., Davos, SW, TMS, Warrendale, PA, V, (1990), 273-278.

62. Won, Y.-M., T.J. Yeo, D.J. Seol and K.H. Oh, A New Criterion for Internal Crack Formation in Continuously Cast Steels, Metall. Mater. Trans. B, 31B, (2000), 779-794.

63. Feurer, U., Mathematisches modell der Warmrissneigung von binären aluminium legierungen, Giessereiforschung 28, 75-80, (1976).

64. Rappaz, M., J.-M. Drezet and M. Gremaud, A New Hot-Tearing Criterion, Metall. Mater. Trans. A, 30A, 2, (1999), 449-455.

65. Drezet, J.M. and M. Rappaz, Prediction of Hot Tears in DC-Cast Aluminum Billets, in Light Metals, J.L. Anjier, ed. TMS, Warrendale, PA, (2001), 887-893.

66. M. M'Hamdi, S. Benum, D. Mortensen, H.G. Fjaer and J.M. Drezet, The importance of viscoplastic strain rate in the formation of center cracks during the start-up phase of direct-chill cast aluminium extrusion ingots, Metall. Mater. Trans. A, 34, (2003), 1941-1952.

67. Cicutti, C., MartinValdez, T. Perez, G. DiGresia, W. Balante and J. Petroni. Mould Thermal Evaluation in a Slab Continuous Casting Machine. Steelmaking Conference Proceedings. 85 (2002), 97-107.

68. Wolf, M.M., Continuous Casting: Initial Solidification and Strand Surface Quality of Peritectic Steels, 9, Iron and Steel Society, Warrendale, PA, (1997), 1-111.

69. Thomas, B.G. and C. Ojeda, Ideal Taper Prediction for Slab Casting, ISSTech Steelmaking Conference, Indianapolis, IN, USA, April 27-30, 2003, 86, (2003), 396-308.

70. Li, C. and B.G. Thomas, Thermo-mechanical Finite Element Model of Shell Behavior in Continuous Casting of Steel, Modeling of Casting, Welding and Advanced Solidification Process X, San Destin, FL, May 25-30, 2003, TMS, (2003), not labelled.

71. Howard, E. and D. Lorento, Development of High Speed Casting, in 1996 Electric Furnace Conference Proceedings, , ISS, Warrendale, PA, Dallas, TX, Dec. 9 12, 1996, (1996). 
BG Thomas and M. Bellet, ASM Handbook, Chap 15, S. Viswanathan ed., submitted October, 2006

72. Miyazawa, K. and K. Schwerdtfeger, Macrosegregation in continuously cast steel slabs: preliminary theoretical investigation on the effect of steady state bulging, Arch. Eisenhutten, 52, 11, (1981), 415422.

73. Lesoult, G. and S. Sella, Analysis and prevention of centreline segregation during continuous casting of steel related to deformation of the solid phase, Solid State Phenomena, 3, (1988), 167178.

74. M. Bellet and A. Heinrich, A two-dimensional finite element thermomechanical approach to a global stress-strain analysis of steel continuous casting, ISIJ International 44, (2004), 1686-1695.

75. Wunnenberg, K. and D. Huchingen, Strand bulging between supporting rollers during continuous slab casting, Stahl und Eisen, 98, 6, (1978), 254-259.

76. Kajitani, T., J.-M. Drezet and M. Rappaz, Numerical simulation of deformation-induced segregation in continuous casting of steel, Metall. Mater. Trans. A, 32, (2001), 1479-1491.

77. N. Triolet and M. Bobadilla, Mastering steel slab internal soundness and surface quality issues through thermomechanical modelling of continuous casting760, in Proc. MCWASP-XI, 11th Int. Conf. on Modelling of Casting, Welding, and Advanced Solidification Processes, C.A. Gandin and M. Bellet, eds., The Minerals, Metals and Materials Society, Warrendale, PA, Opio, France, May 28 - June 2, 2006, (2006), 753-760. 